SERI/PR-231-2272

UC Category: $61 \mathrm{a}$

\title{
SERI Aquatic Species Program 1983 Annual Report
}

March 1984

Prepared under Task No. 4625.10

Solar Energy Research Institute

A Division of Midwest Research Institute

1617 Cole Boulevard

Golden, Colorado 80401

Prepared for the

U.S. Department of Energy

Contract No. DE-AC02-83CH10093 


\section{NOTICE}

This report was prepared as an account of work sponsored by the United States Government. Neither the United States nor the United States Department of Energy, nor any of their employees, nor any of their contractors, subcontractors, or their employees, makes any warranty, express or implied, or assumes any legal liability or responsibility for the accuracy, completeness or usefulness of any information, apparatus, product or process disclosed, or represents that its use would not infringe privately owned rights. 


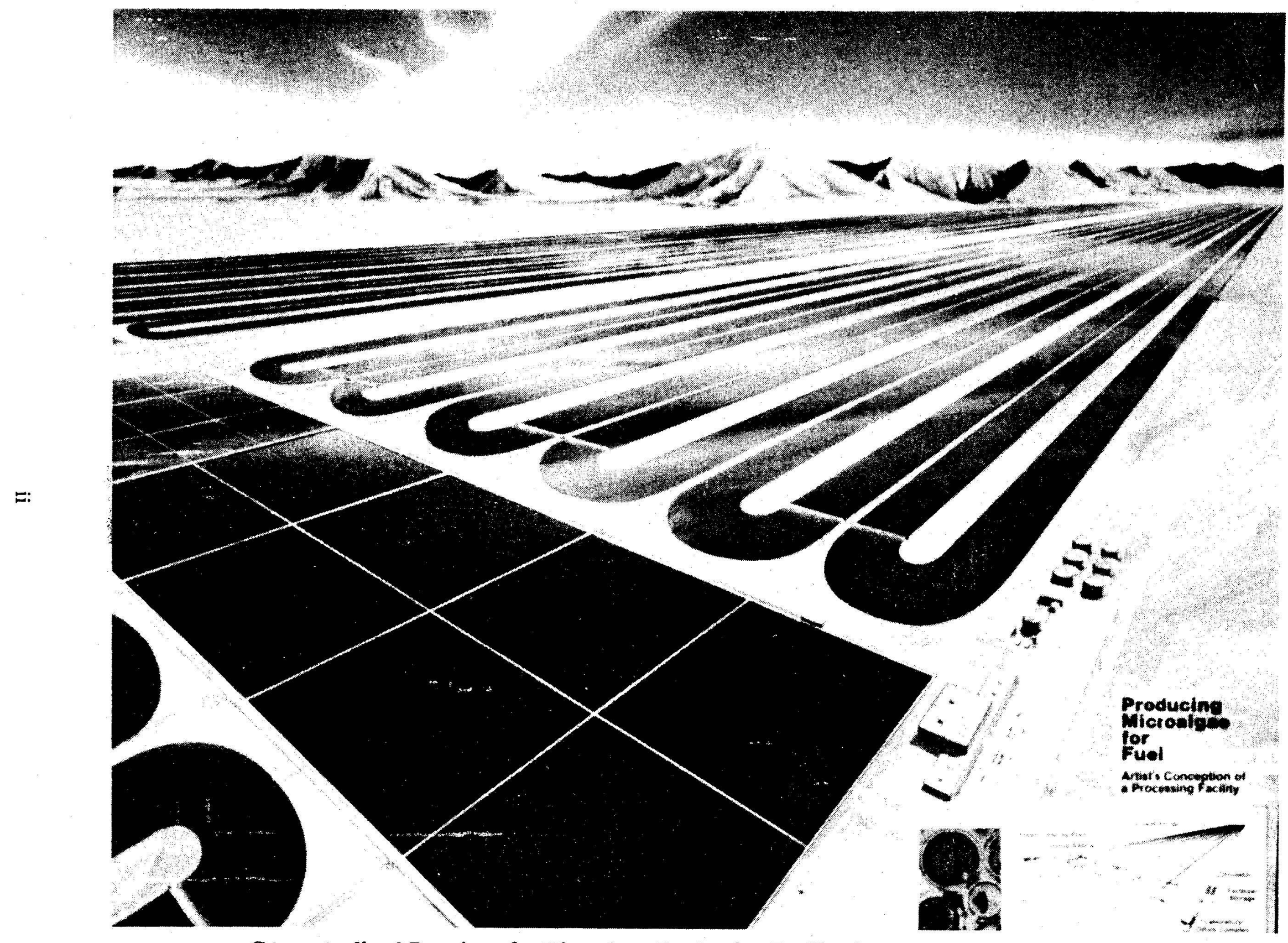

Conceptualized Drawing of a Microalgae Production Pacility in the American Southwest 


\section{PREFACE}

This report is the final 1983 annual report for the SERI/DOE Aquatic Species program. The program is funded through the Biomass Energy Technology Division of the U. S. Department of Energy.

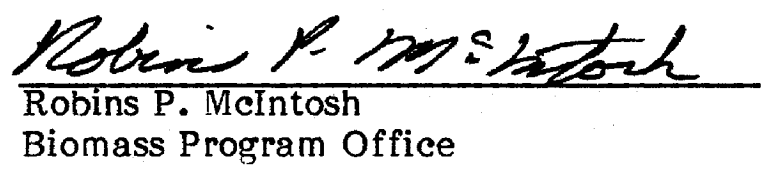

Approved for

SOLAR ENERGY RESEARCH INSTITUTE

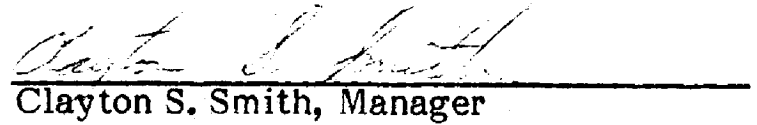
Solar Fuels Research Division 


\section{SUMMARY}

\section{Objective}

To improve the productivity, conversion to fuels, and cost efficiency of aquatic plant species cultivated for energy. The emphasis is on developing oil-yielding microalgae that will grow in the saline waters of the desert in the American Southwest.

\section{$\underline{\text { Discussion }}$}

During 1983 research was carried out under three tasks: biological, engineering, and analysis. Biological research was aimed at screening for promising species of microalgae, macroalgae, and emergent plants that could be cultivated for energy products. Promising species were studied further to improve yields. Engineering research involved the operation and comparison of two microalgae culture concepts: a shallow raceway and a deeper pond system. Research was initiated into developing more efficient harvest systems. The analysis task is designed to support technology development through the determination of cost goals, resource assessments, and technology evaluations. This year an economic model was developed that permits evaluation of the state of the art for microalgae culture.

\section{Conclusion}

The major accomplishments for 1983 in the Aquatic Species program were as follows:

- The collection and isolation of over 100 species of microalgae from desert saline waters

- Characterization of growth and lipid composition of 10 species of microalgae

- Operation and characterization of the performance of two outdoor facilities

- Composition of an economic model for the assessment of microalgal production cost

- Cortinued improvement of macroalgae and emergent plant culture systems. 


\section{TABLE OF CONTENTS}

1.0 Introduction $\ldots \ldots \ldots \ldots \ldots \ldots \ldots \ldots \ldots \ldots \ldots \ldots \ldots \ldots \ldots \ldots \ldots \ldots \ldots, 1$

2.0 Program Element: Aquatic Species ...................... 2

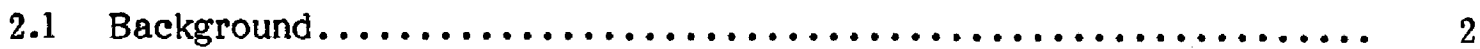

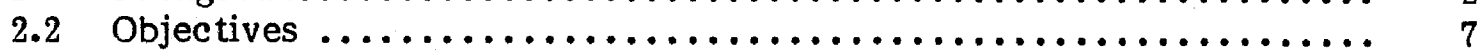

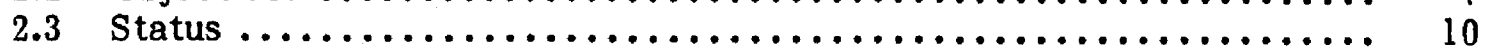

2.3.1 Biological Research ........................... 10

2.3.2 Engineering Research and Development ............... 29

2.3.3 Technology Analysis ......................... 36

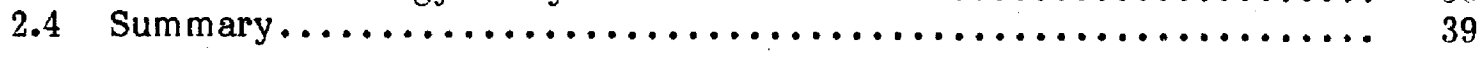

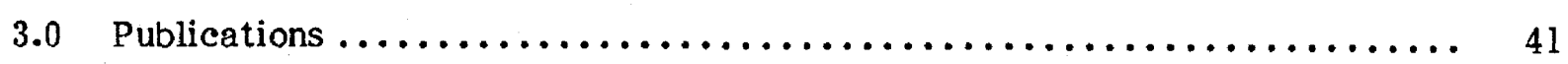




\section{LIST OF FIGURES}

Page

2-1a Cells of the Microalga Chlorella That Have Been Stained for Oils ........ 3

2-1b Oils from Microalgae Fractionated into 5 Classes: Hydrocarbons

Isoprenoids, Triglycerides, Glycolipids, and Phosopholipids ........... 3

2-2a Shallow Raceway System Operated in Hawaii $\ldots \ldots \ldots \ldots \ldots \ldots \ldots \ldots \ldots \ldots$

2-2b Deeper Pond System Operated in California $\ldots \ldots \ldots \ldots \ldots \ldots \ldots \ldots \ldots \ldots$

2-3a Locations of Saline Groundwater Reservoirs in the Southwest

United States .................................... 8

2-3b Typical Southwest Desert Area......................... 8

2-4 Modified Burial Vaults at Harbor Branch Are Ideal for Screening Macroalgae for Growth $\ldots \ldots \ldots \ldots \ldots \ldots \ldots \ldots \ldots \ldots \ldots \ldots \ldots \ldots \ldots \ldots \ldots$. 11

2-5 Relative Oxygen Production vs. $\mathrm{pH} \ldots \ldots \ldots \ldots \ldots \ldots \ldots \ldots \ldots \ldots \ldots \ldots \ldots$

2-6 Schematic of Strategy for Comprehensive Screening of Microalgae Strains ................................. 16

2-7a Collection of Microalgae from Saline Desert Regions................ 17

2-7b Growth Studies of Selected Species Using Chemostats ............. 17

2-7e Studies of the Lipid Fractions Produced by the Microalgae $\ldots \ldots \ldots \ldots \ldots \ldots$

2-8 General Locations of Areas Sampled in the Desert of Eastern Calif ornia and Western Nevada............................. 19

2-9a Ankistrodesmus falcatus Isolated from Pyramid Lake $\ldots \ldots \ldots \ldots \ldots \ldots \ldots$

2-9b Increases in Optical Density of Pyramid Lake Ankistrodesmus Cultures Grown on Nitrate and Urea $\ldots \ldots \ldots \ldots \ldots \ldots \ldots \ldots \ldots \ldots \ldots, 23$

2-10 Growth Curve of Ankistrodesmus Showing Response to Salinity

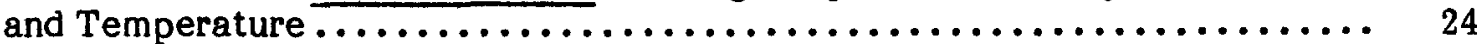

2-11 Physiological Responses of Chlorella Nitrogen-Limitation............. 28

2-12 Changes in Cell Volume as a Result of Nitrogen Deprivation .......... 28

2-13 Cost of Production Versus Market Volume $\ldots \ldots \ldots \ldots \ldots \ldots \ldots \ldots \ldots \ldots \ldots$

2-14 Algal Production Flume, Including Location of Heat Exchanger, Lift Box, Drain Box, and Airlift System 


\section{LIST OF FIGURES (Continued)}

Page

2-15 Pond System Operated by Microbial Products Co. $\ldots \ldots \ldots \ldots \ldots \ldots \ldots \ldots$

2-16a Systematic Mixing Resulting from Foils Inserted in the Shallow Raceway ....................................... 34

2-16b Ratio of Growth Rate under Ideal Flashing Light Regime to Growth Rate in Absence of Flashing Light Effect as a Function of Incident Irradiance and Areal $\mathrm{Chl}$ a Concentration.................... 34

2-17 Production in Experimental Flumes as a Function of $\mathrm{pH}$

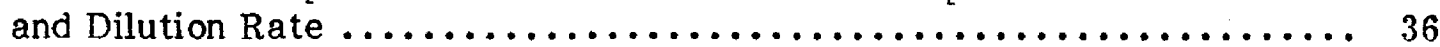

2-18a Resource Data Mapping from Baseline Parameter Maps through Intermediate Composite Maps to the Final Composite Stratification Map .......................................... 37

2-18b Computer-Generated Composite Map of Overall Suitability for Microalgae Culture ............................... 


\section{LIST OF TABLES}

Page

2-1 Composition of Microalgae, Macroalgae, and Emergent Plants as Found in Natural Stands and, in the Case of Microalgae, after

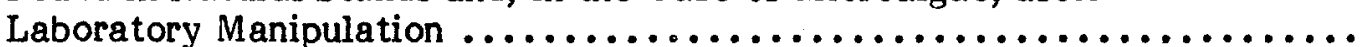

2-2 Aquatic Species Program Tasks, Subtasks, Projects, and Principal

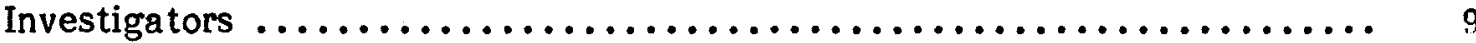

2-3 Lipid Composition of Selected Macrophytes $\ldots \ldots \ldots \ldots \ldots \ldots \ldots \ldots \ldots \ldots \ldots$

2-4 Cultures of Desert Algae Isolated and Maintained by the Scripps

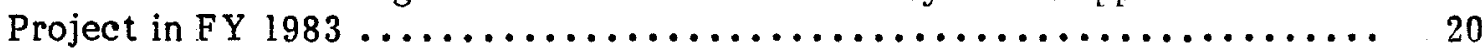

2-5 Yields and Proximate Cellular Chemistry of Selected Desert Microalgae ........................................ 22

2-6 Responses of Some Saline Desert Algae to Temperature and

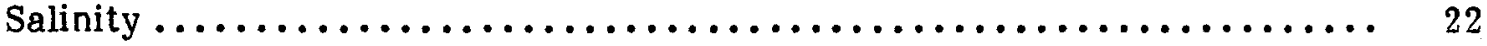

2-7 Proximate Cellular Composition of Unicellular Algae Grown Under Optimal, Nitrate-Deficient, or Salt Stress Conditions .............. 25

2-8 Fractionation of Algal Lipids on Unisil Columns ................. 26

2-9 Comparison of Growth Responses and Lipid Content of Six Strains

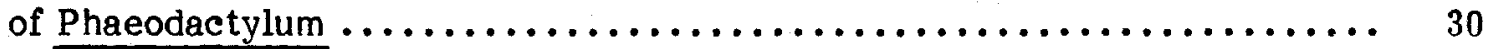

2-10 Performance Data from Raceway and Pond Systems ............. 35

2-11 Chemical Characteristics of Water from California and Nevada Desert Regions ................................... 38

2-12 World Oil Price Projections for High, Middle, and Low World Oil Price Scenarios, 1983 to 2000 


\section{SECTION 1.0}

\section{INTRODUCTION}

The purpose of the Aquatic Species program is to improve the productivity, conversion to fuels, and cost efficiency of aquatic plant species for energy. The emphasis of the program is on developing oil-yielding microalgae with will grow in the saline waters of the desert in the A merican Southwest. To meet this objective, research is carried out under three tasks: biological, engineering, and analysis. The principal objectives of the biological task are (1) to conduct a comprehensive and complete screening activity that will result in the selection of the best microalgae strains for production of fuels; (2) to establish a gene pool so that species can be improved through agronomic means; and (3) to develop techniques that will result in enhancing the yields of the desired fuel product. Engineering research is concerned with integrating biological concepts with engineering principals to develop the most cost-effective microalgal culture technology. Work is concentrated on developing culture management strategies and required subsystems such as harvesting technologies. Analysis supports the technology development through cost goal determination, resource assessment, and technology evaluation. The program also supports the development of macroalgae culture for methane gas or alcohols and emergent plant culture for alcohols. 


\section{SECTION 2.0}

\section{PROGRAM ELEMENT: AQUATIC SPECIES}

\subsection{BACKGROUND}

The worldwide energy shortage and Arab oil embargo of the early 1970 s encouraged many nations to look for new sources of oil, electricity, and gas. Renewable resources such as biomass were often highlighted as a long-term solution to the energy problem, due to their nondepletable, renewable nature. While the first biomass sources considered were the readily available ones such as corn or wood, it was apparent that new biomass sources should also be developed, among them aquatic plant species. Aquatic plant species may be divided into three distinct groups: macroalgae, emergent plants, and microalgae. Macroalgae range in size and morphology from small simple filamentous plants to very large, complex seaweeds, such as Macrocystis (giant kelp). Macroalgae may grow attached (Macrocystis) or free floating (Sargassum, Gracilaria). The predominant storage product of macroalgae is carbohydrate, which can be harvested for fermentation to methane or alcohol. Emergent plants are vascular plants common to bogs, and fresh or salt marshes, rooted in the substratum. Familiar genera with potential for energy production include Typha (cattail), Scripus (rush), and Phragmites (reed). The emphasis of the Aquatic Species program has been on the production of microalgae (Figure 2-1). Microalgae are unicellular plants that range in size from 1 to $10 \mathrm{~m}$.

The production of microalgal biomass has been studied for about 4 decades. Its potential to provide food, feed, and energy for mankind has been the reason for increasing interest in these organisms. Microalgae also contain high amounts of fats and oils (lipids). They are produced by direct use of the sun's energy via photosynthesis. In principle, lipids from microalgae are suitable for refining into conventional liquid fuels. Indeed, in the past, biological oils have been refined to fuels during shortages in petroleum supply. In 1980, Aaronson and Dubinsky proposed using saline water resources in arid lands to produce microalgae for oils. They also projected that these microalgal oils could be used as a source of fuel.

The chemical composition of these microalgae includes three classes of organic compounds-proteins, carbohydrates, and lipids-and a fourth class-inorganic minerals. Proteins are either enzymatic or structural. Enzymes act as catalysts in the metabolism of the cell. It is the high protein content (up to $60 \%$ ) that makes the microalgae metabolic factories. Carbohydrates are used by the cell for energy storage (sugars, and starch) or have a structural function (cellulose). Macroalgae and emergent plants are extremely high in carbohydrates (up to $85 \%$ of the organic weight). Lipids are compounds that, like carbohydrates, may be used for energy storage (triglycerides) or have structural functions (phospholipids in the membrane).. Lipids have the highest energy content per unit weight of the three classes of compounds (lipid, $9.2 \mathrm{kcal} / \mathrm{g}$; carbohydrate, $3.7 \mathrm{kcal} / \mathrm{g}$; protein, $5.7 \mathrm{kcal} / \mathrm{g}$ ). They may be utilized directly as liquid fuel replacement products, and thus are of great interest as a renewable energy source. Certain microalgae, such as diatoms, synthesize large quantities of lipids.

The metabolic states of photosynthetic organisms may be changed as well as the cellular chemical compositions, by culture manipulation. Thus potential exists for manipulating plants to produce large quantities of the desired energy products. Table 2-1 presents data on the plant composition found in nature and, for microalgae, the composition after culture manipulation. As indicated lipid composition is highly variable and can be drastically increased through culture manipulation. 


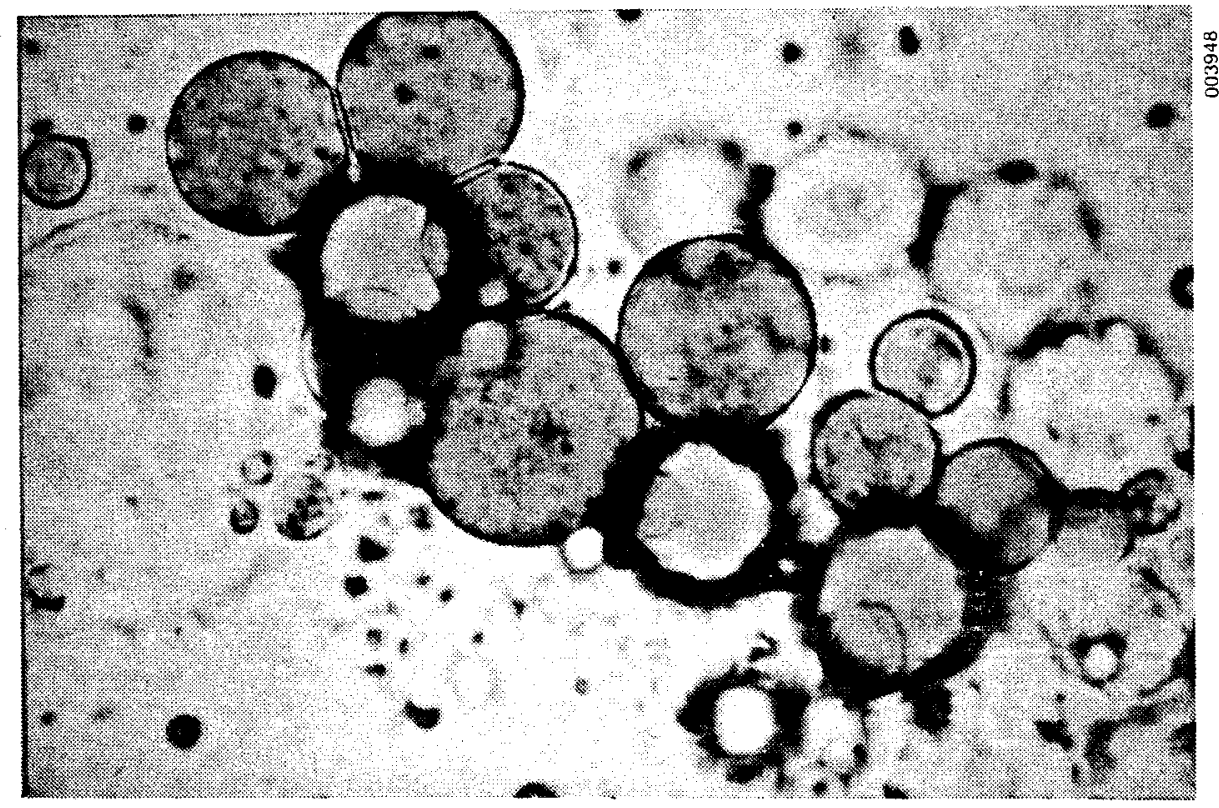

Figure 2-1a. Cells of the Microalga Chlorella That Have Been Stained for Oils (50\% of dry weight)

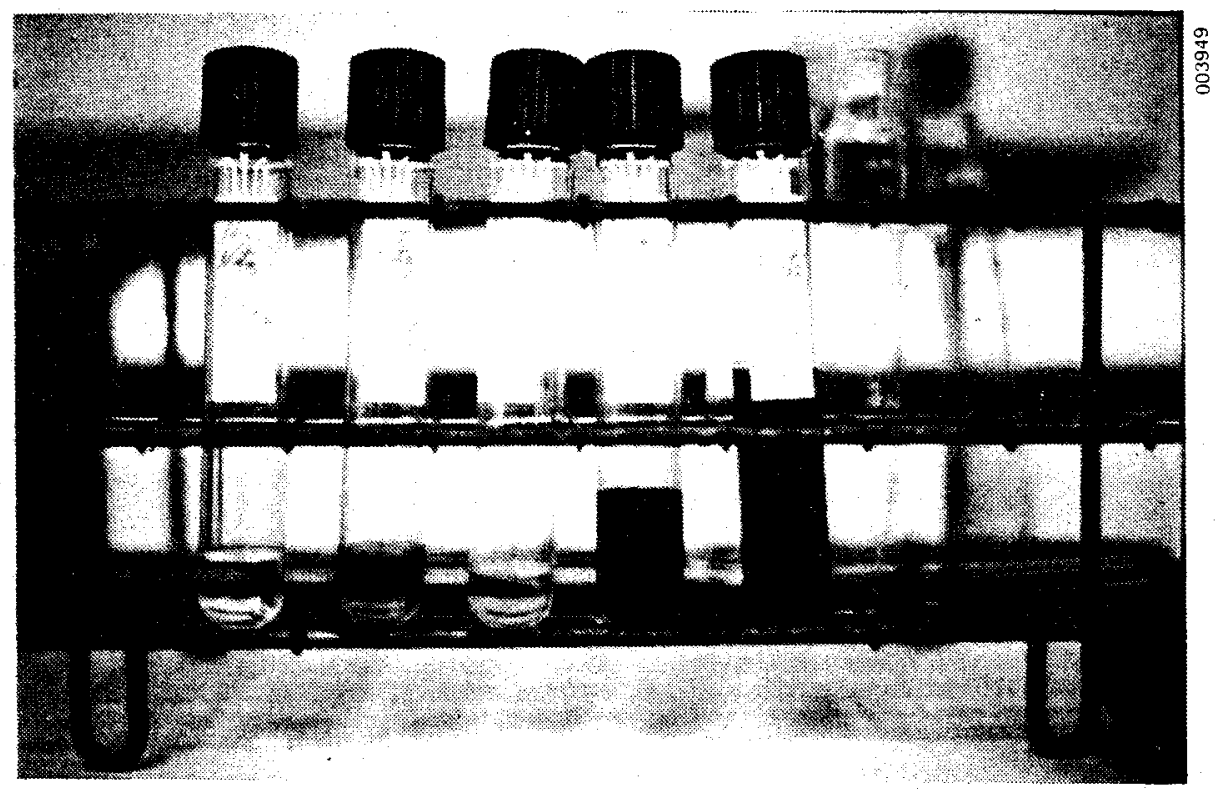

Figure 2-1b. Oils from Microalgae Fractionated into 5 Classes: Hydrocarbons, Isoprenoids, Triglycerides, Glycolipids, and Phosopholipids 
Table 2-1. Composition of Microalgae, Macroalgae, and Emergent Plants as Found in Natural Stands and, in the Case of Microalgae, after Laboratory Manipulation

\begin{tabular}{lcccc}
\hline & \multicolumn{2}{c}{ Microalgae } & $\begin{array}{c}\text { Natural } \\
\text { Macroalgae }\end{array}$ & $\begin{array}{c}\text { Natural } \\
\text { Emergents }\end{array}$ \\
\cline { 2 - 4 } & Natural & Manipulated & $73-85$ & $70-85$ \\
\hline${\text { Carbohydrate }(\%)^{\mathrm{a}}}^{\text {Protein }(\%)^{\mathrm{a}}}$ & $20-30$ & $5-90$ & $12-20$ & $4-10$ \\
Lipid (\%) & $50-60$ & $10-60$ & $3-7$ & $2-7$ \\
Ash $(\%)^{\mathrm{b}}$ & $7-25$ & $7-70$ & $25-49$ & $3-8$ \\
Moisture $(\%)^{\mathrm{b}}$ & $8-36$ & $8-36$ & $88-92$ & $60-70$ \\
\hline a Percentage of dry, ash-free weight. & $88-92$ & $88-92$ & & \\
b Percentage of total weight. & & &
\end{tabular}

Since 1982 the emphasis of the Aquatic Species subprogram has been to develop a technology for the mass culture of microalage utilizing saline resources in arid areas of the American Southwest. The primary productivity of these areas has been measured at 0$0.7 \mathrm{~g} \mathrm{~m}^{-2}$ day $^{-1}$. Primary productivity is limited by a lack of suitable water. It is estimated that by using brackish water resources, microalgal production could exceed $50 \mathrm{~g} \mathrm{~m}^{-2}$ day $^{-1}$. The research supported by this program is organized into three tasks: Biological Research, Engineering Research, and Technology Analysis.

The focus of the biological research is on increasing the oil yield from cultured microalgae. To do this, researchers are selecting the most promising species, domesticating these species through genetic manipulation and classical agronomic practices, developing culture techniques that maximize biomass production, and learning to manipulate cellular metabolism so that the sun's energy is converted into the most desirable fuel products (i.e., lipids, oils).

In selecting the most promising microalgae, researchers are conducting a comprehensive survey of microalgae. Microalgae with the following characteristics will be considered the best species for fuel production:

- Rapid growth rate at high cell density

- High energy content (lipids and hydrocarbons)

- Wide environmental tolerance range (temperature, salinity)

- Minimal requirements for media supplementation (addition of vitamins, trace minerals)

- Sustainable monoculture in outdoor culture.

Once the best species are selected, genetic manipulations may be used to domesticate the microalgae to produce the greatest yields in mass culture. This will be very similar to the process used in modern agriculture to improve yields. Techniques similar to those used in agronomics to improve wheat and corn yields will be used. Selection of strains 
that are highly productive and have large portions of carbon being allocated to oils will be given priority. Techniques will be developed to genetically cross strains to develop superior strains of microalgae for oil production. Presently the program is involved in assembling and characterizing a genetic pool for such efforts.

Work is being performed to define the best culture conditions for the most promising species. To optimize microalgal culture, light, nutrient (nitrogen, phosphorus, trace metals), carbon $\left(\mathrm{CO}_{2}, \mathrm{HCO}_{3}^{-}\right), \mathrm{pH}$, temperature, and salinity requirements must be defined and understood in terms of yield-cost trade-offs.

Finally, as mentioned previously, manipulation of the culture can alter cellular metabolism so that the cell synthesizes desirable fuel products. "Hitting the lipid trigger" is a phrase of ten used to express this phenomenon; that is, switching cellular metabolism from a growth phase, characterized by rapid cell division, to a lipid accumulation phase. This has been accomplished by imposing stresses on the cells, such as an osmotic shock or nitrogen deprivation. Basic lipid metabolism is being studied, so that in the future the cells' metabolic machinery can be manipulated to permit the cell to synthesize the most desired lipids in terms of fuel utilization. An example would be to switch the cell from synthesizing structural polar lipids to neutral storage lipids.

The purpose of engineering research is to integrate biological concepts with engineering principles to develop a cost-effective microalgal culture technology. An example of this is developing culture systems that most efficiently utilize the flashing light effect. Algal productivity has been demonstrated to be increased by exposing cells to regular flashes of light. This may be accomplished by mixing cells so that they move from the dark areas within the culture to the surface at regular intervals.

The most critical microalgal production design considerations are the depth of the culture, the mixing strategy, and the enclosure configuration. The choices involve tradeoffs in algal productivity, environmental control, system capital, and operating costs. The subprogram is supporting the operation of two systems of differing depth and channel configuration. A shallow raceway system (10 cm depth) (Figure 2-2a) is being operated in Hawaii. Shallow systems have the advantage of developing higher cell concentrations, well above $1 \mathrm{~g} / \mathrm{L}$. This minimizes the volume that must be handled by the harvesting process, makes more efficient use of added nutrients, and increases the capacity for manipulation of the chemical composition of the cultured alga. Also, the flow characteristics of shallow systems are more easily manipulated. Foils placed in the Hawaiian system cause regular patterns of induced turbulence, which allows the culture to utilize a flashing light effect. The addition of foils has doubled productivity.

Microbial Products, Inc., is operating a deeper pond system $(20 \mathrm{~cm})$ (Figure 2-2b) in California. Deep systems have the advantage of natural temperature control, but the greater light limitation results in reduced cell concentrations. 'The reduced cell concentration increases the cost of harvesting the algae.

Microalgal cultures must be mixed to prevent cell settling or flotation, to prevent thermal stratification, and to ensure adequate contact between the algae and its nutrients. Mixing costs are the highest of the various power costs of these systems. Since the power required is proportional to the cube of the velocity for a given volumetric flow, it is important to minimize culture velocity while maintaining adequate mixing. 


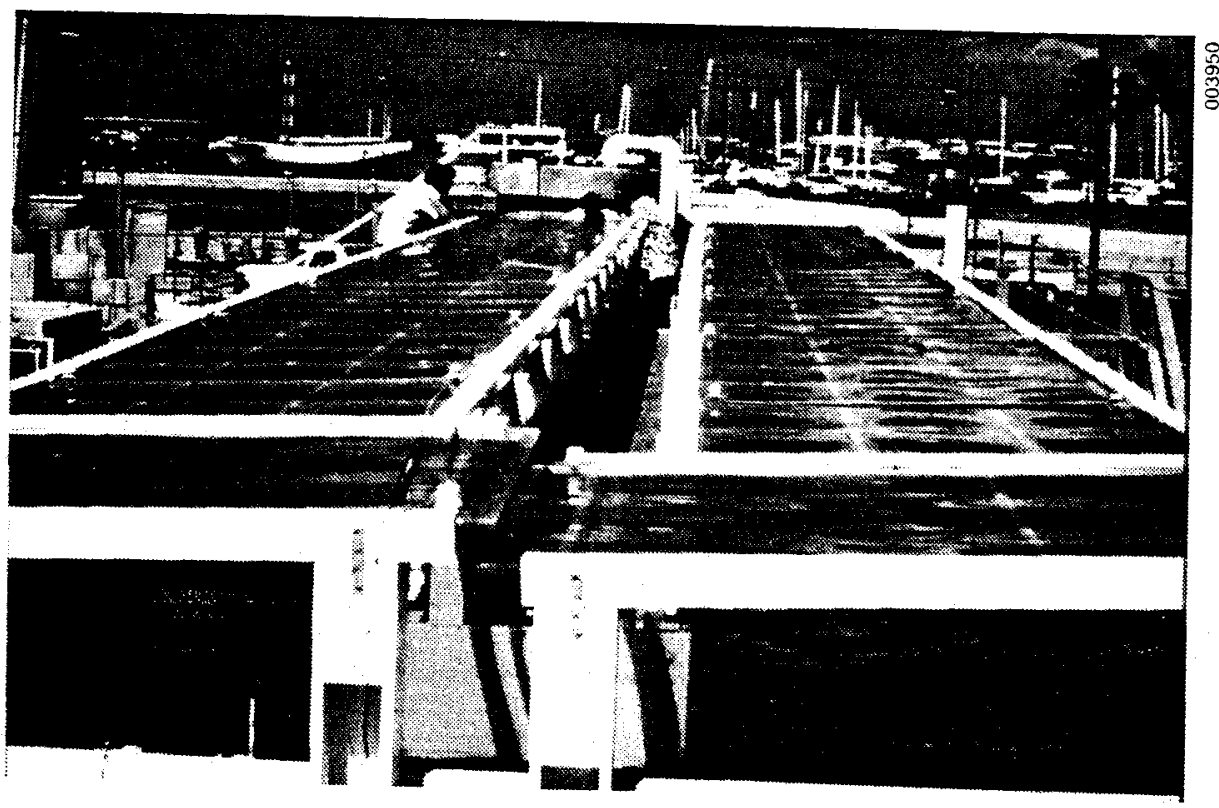

Figure 2-2a. Shallow Raceway System Operated in Hawaii

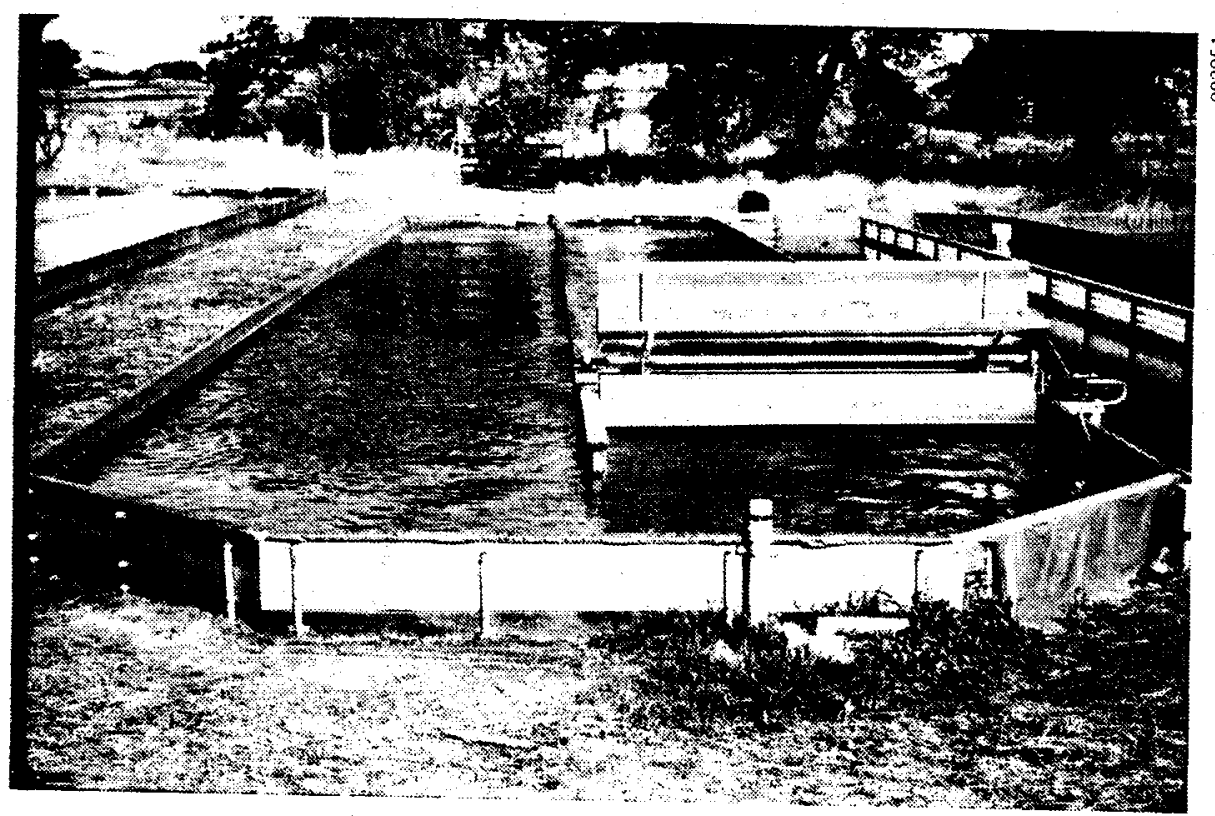

Figure 2-2b. Deeper Pond System Operated in California 
The development of culture management techniques is another area of engineering research. Culture management alternatives are needed that lead to higher sustained yields of energy products. Two culture strategies are common: batch and continuous. In batch culture a pond is innoculated, and the microalgae are allowed to grow to a point at which all algae in the pond are harvested. In continuous culture a portion is harvested daily and makeup water added to the culture.

To determine which type of design-the shallower raceway or deeper ponds-is more cost-effective, it is necessary to project the costs of building and operating each system at the time the technology is scheduled for commercialization (10 to 15 years hence for microalgae). To do this, the supply and demand of the required inputs (water, carbon, nutrients, and energy) must be calculated, as must the market potential for the intended products. This task is the objective of the third area of research in the Aquatic Species subprogram-technology analysis. There are two subtasks in analysis: resource assessment and economic analysis. The resource assessment subtask is concerned with detailing the availability of required resources, and the economic evaluation subtask with determining cost/benefit ratios and ultimate marketability analyses.

Sunlight, land, and water are the most basic required resources. Careful study has shown the American Southwest to be best suited to fulfill these requirements. It is an area with high insolation, a large amount of land with few competitive uses, and a vast supply of saline water available in underground aquifers (see Figure 2-3).

Carbon, nitrogen, and phosphorus are the resources needed in the next greatest guantities. Potential carbon sources in the form of $\mathrm{CO}_{2}$ include commercial $\mathrm{CO}_{2} ; \mathrm{CO}_{2}$ trapped in geologic formations in the Southwest; and $\mathrm{CO}_{2}^{2}$ from mining and processing of calcium carbonate in the Southwest, from power plant stack gases, from synthetic fuel plant waste streams, and from biogas produced by anaerobic digestion of organic by-products or waste streams from algal facilities. Bicarbonate is an alternative source of carbon for some microalgae species. Initially nitrogen and phosphorus must be added to cultures, but researchers expect that $90 \%$ of the nitrogen removed with the algal biomass at harvest will be recycled back to the culture.

In summary, the Aquatic Species subprogram supports research on the development of microalgae, macroalgae, and emergent plants as a source of renewable fuels. It is the objective of biological research to identify, culture, evaluate, and manipulate aquatic species to produce sustained yields of high-value energy products. The engineering research is concerned with design, evaluation, construction, and testing of the components and processes that will be required to produce these yields. The technology analysis efforts identify the resources required and available and evaluate the economics of a mass-production system.

\subsection{OBJECTIVES}

The overall objective of the Aquatic Species subprogram is to define and improve the productivity, conversion to fuels, and cost efficiency of aquatic plant species cultivated for energy. Table 2-2 lists the tasks, subtasks, and projects of the AS subprogram. 


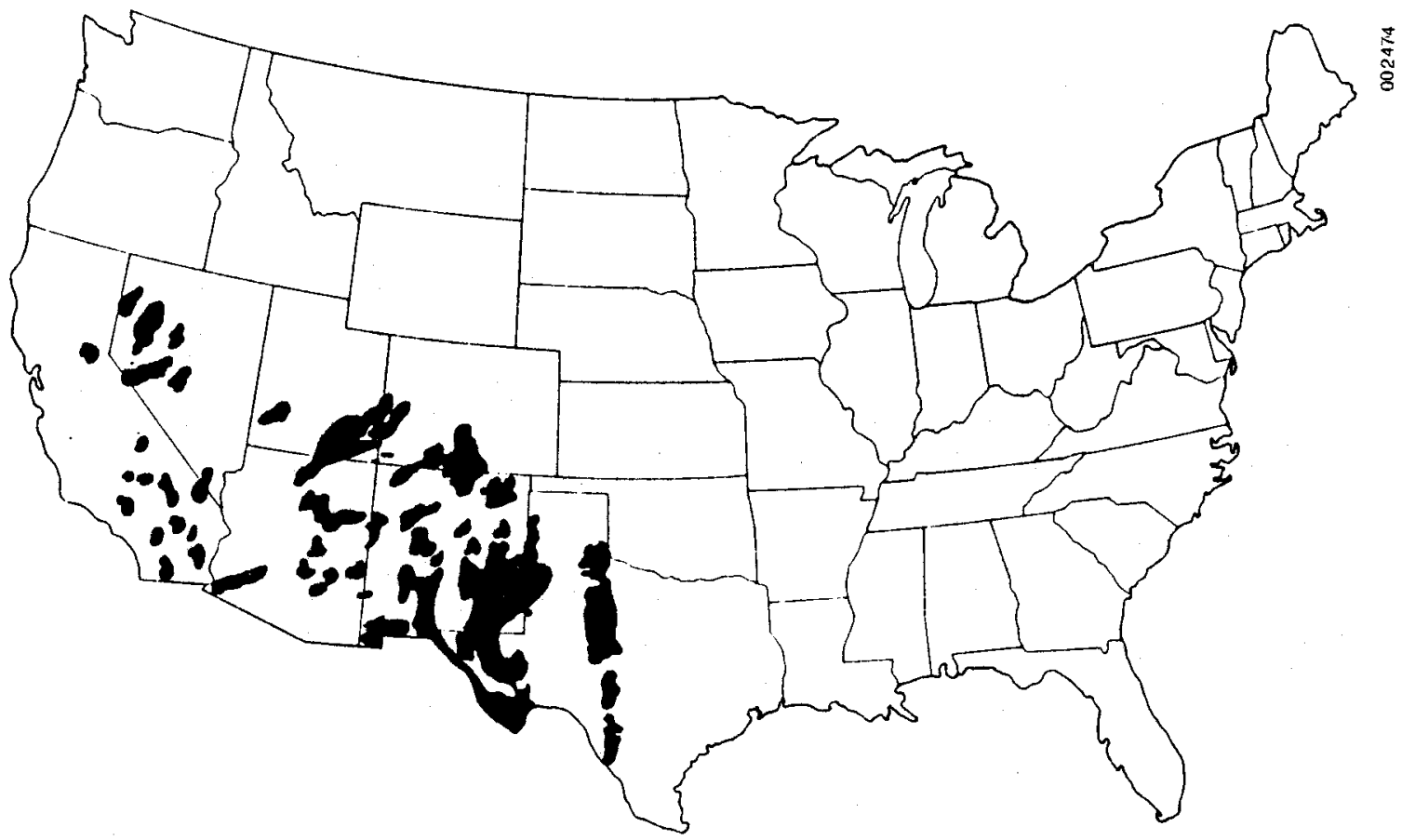

Figure 2-3a. Locations of Saline Groundwater Reservoirs in the Southwest United States

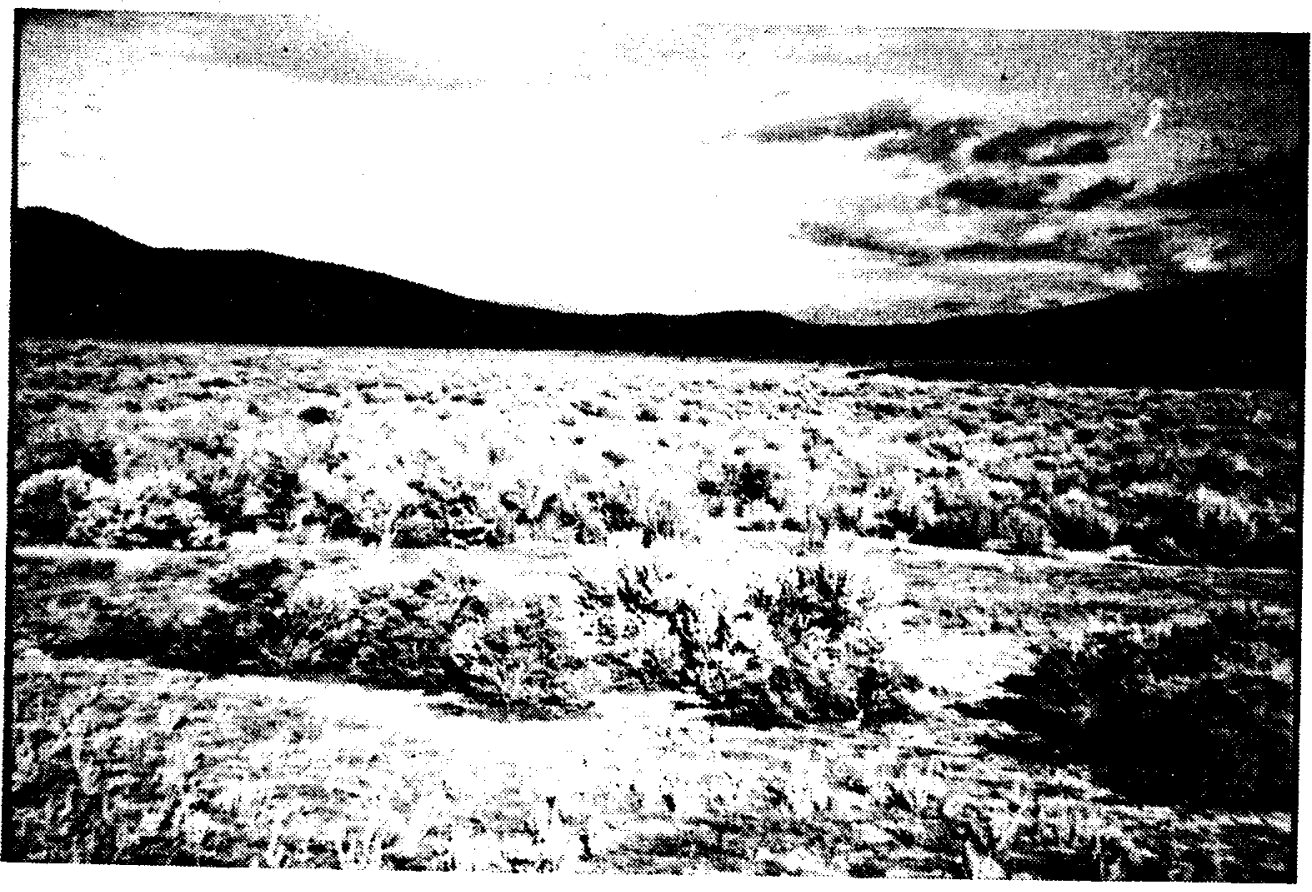

Figure 2-3b. Typical Southwest Desert Area 
Table 2-2. Aquatic Species Program Tasks, Subtasks, Projects, and Principal Investigators

\section{Task I: Biological Research}

\section{A. Species Screening and Culture}

Emergents

University of Minnesota - Wetland Biomass Production-Douglas Pratt

Macroalgae

Harbor Branch Institute-Cultivation and Conversion of Marine Macroalgae-John Ryther Microalgae

Scripps Institution of Oceanography-Collection and Selection of Oil-Producing Microalgae-William Thomas

Georgia Institute of Technology-Chemical Profiles of Microalgae-Thomas Tornabene

Solar Energy Research Institute-Microalgae Oils Technology-Lawrence Raymond

Ben Gurion University-Development of Outdoor Raceway Capable of Culturing Oil-Rich Halotolerant Microalgae-Shoshana Arad

\section{B. Species Improvement}

Solar Energy Research Institute-Algal Oils $R \& D-$ Steve Lein

Solar Energy Research Institute-Photophysics and Photochemistry of Algal and Bacterial Pigments-John Connolly

Task II: Engineering Research

\section{A. Design Coordination}

Jaycor-Biological and Engineering Parameters of Algal Mass Culture-Les Levine

Science Applications, Inc.-Microalgal Systems Simulation-William Hubka

\section{B. Component Development}

No subcontracts

\section{Experimental Facilities}

University of Hawaii-Sustaining Yield Performance of Shallow Algal CulturesEdward Laws

Microbial Products, Inc.-Production of Liquid Fuels and Chemicals from MicroalgaeJohn Benemann and Joel Weismann

\section{Task III: Technology Analysis}

Solar Energy Research Institute-Resource Assessment for Aquatic Biomass ProductionEugene Maxwell

Solar Energy Research Institute-Cost Budgeting of Microalgal Facilities-Andrew Hill 


\subsection{STATUS}

\subsubsection{Biological Research}

Aquatic microorganisms such as algae represent a major potential source of photosynthetically produced biomass. Their inherent rapid growth characteristics, combined with diverse chemical compositions, represent a significant resource for the production of fuels and other chemicals.

Because of their high yields and efficiencies of light utilization compared to higher plants, microalgae are attractive potential sources of biomass for energy and protein production. Program emphasis is being placed on aquatic species that produce lipids, which may be used as fuel or petrochemical replacements and may be grown in the saline or brackish waters of the American Southwest desert.

Biological research is divided into two subtasks: species screening and culture, and species improvement. Species screening and culture is concerned with selecting the best species and developing cost-effective methods of culturing those species. Species improvement is concerned with enhancing the performance characteristics of the best species through culture manipulation, metabolic regulation, and genetic techniques. The program has been involved in the screening and culture of macroalgae, emergents, and microalgae. Emphasis has been placed on improving macroalgae species.

\subsubsection{Species Screening and Culture}

Macroalgae. The original concept of an energy farm based on the production of macroscopic algae was the open-ocean farm, a suspended framework structure, buoyed and moored at depths of $700 \mathrm{~m}$ or more in the open ocean, to which plants like the giant kelp (Macrocystis pyrifera) would be attached. Nutrient-rich bottom water would be pumped through a pipe to the surface and through the kelp plants as their source of nourishment. Costs of pumping the deep water to the surface and other aspects of the system associated with its deep sea and open ocean location caused initial doubts about its economic feasibility and cost-effectiveness. A small test module was anchored off the coast of California in 1978 and was, from the start, beset with numerous technical problems; it sank to the ocean bottom before any useful data was obtained.

An alternative concept was a land-based energy production system utilizing saline waters from underground aquifers or enclosed coastal areas. Work on this concept was begun in 1979 and transferred to the Harbor Branch Institute, where the work was carried out in FY 1983. Research began with a screening program designed to evaluate growth and biomass production of all macroscopic algal species that could be obtained in adequate quantity in the central Florida area. A total of 42 species were grown in specially adapted burial vaults (Figure 2-4). These included 16 green algae (Chlorophyta), 2 brown algae (Phaeophyta), and 18 red algae (Rhodophyta). Of these, the most successful and suitable species were a strain of Gracilaria (a red seaweed) and Ulva (a green seaweed). These two species have a high carbohydrate content that may be anaerobically digested to methane gas. The demonstrated energy yields of Gracilaria and Ulva are $2.5 \times 10^{6}$ and $3.0 \times 10^{6} \mathrm{~J} / \mathrm{m}^{2}$ day, respectively.

Gracilaria may be grown in channels or raceways on land or in shallow coastal waters in tropical to semitropical latitudes. At an offshore site, the seaweed would presumably be 


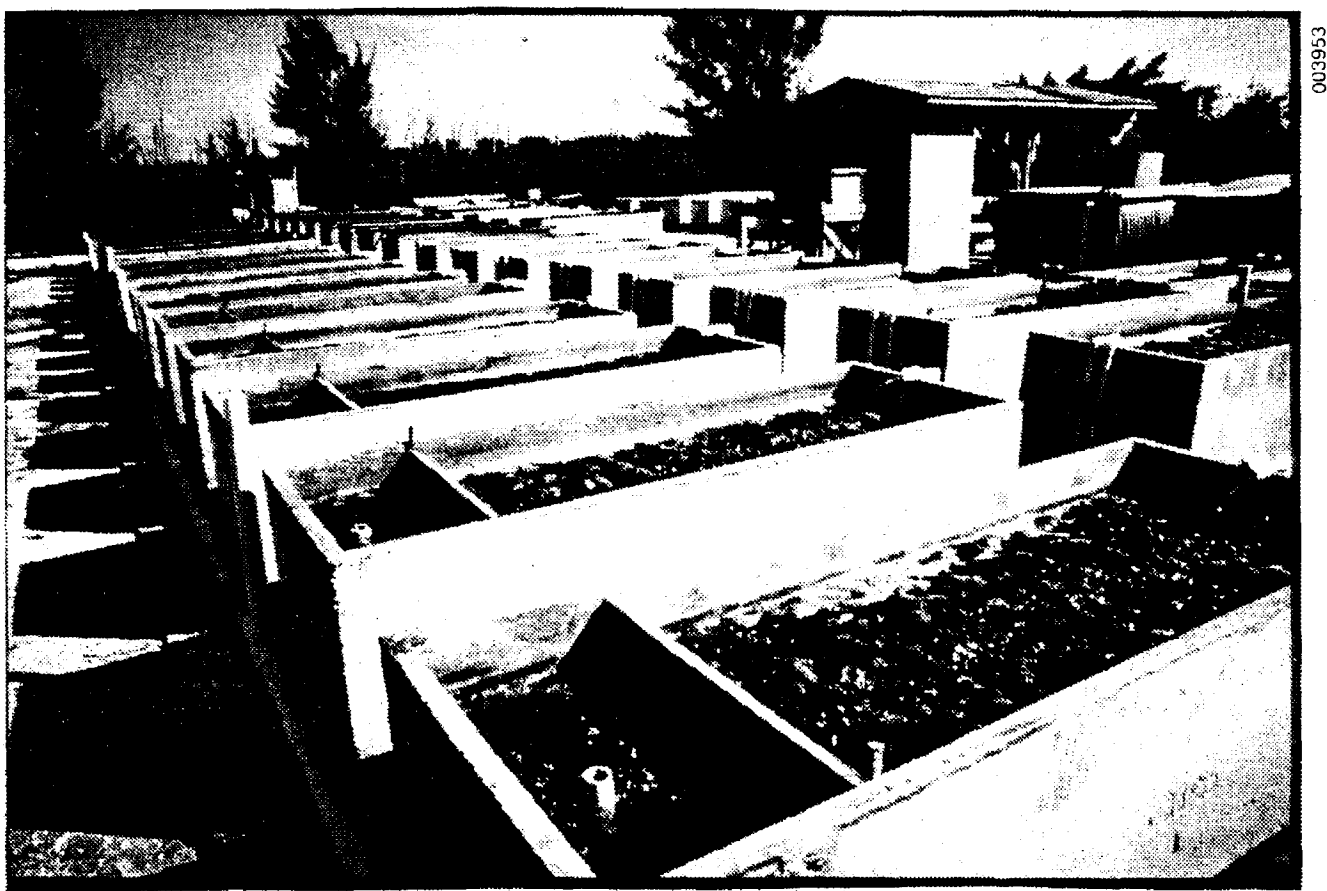

Figure 2-4. Modified Burial Vaults at Harbor Branch Are Ideal for Screening Macroalgae for Growth

confined by a fence or other barrier. Within the enclosure, the culture is maintained at a density of approximately two kilograms wet weight per square meter. At this density, the algae is compacted such that normal wind and tidal action will not cause the algal mass to drift and accumulate unevenly. At brief intervals during the day, the culture is mixed and rotated by compressed $\mathrm{CO}_{2}$ from pipes distributed throughout the culture systems.

Well-nourished Gracilaria exposed to full sunlight at such latitudes will double its biomass in 1 to 4 weeks, depending on the season, water flow, and other variables. Af ter its biomass has doubled (i.e., from 2 to $4 \mathrm{~kg} / \mathrm{m}^{2}$ ) the incremental grow th is harvested to return the crop to a starting density that will ensure continued optimal yield. The doubling of biomass will be accompanied by the utilization of all stored nutrients and a reduction of elemental nutrients in the plant tissues to roughly half the initial concentrations. Enrichment of the new starting crop following harvest could conceivably be accomplished onsite at the seaweed farm, but the rapid uptake and storage of nutrients by depleted seaweeds makes possible a simpler, more efficient enrichment process, known as pulse fertilization.

During the past year research has focused on reducing energy inputs to the culture system. In particular, aeration frequency, water turnover rates, and carbon utilization have been investigated. To determine the trade-off between operating costs and yield, researchers are assessing $\mathrm{CO}_{2}$ addition and frequency of aeration. A series of gas diffusion experiments was conducted to determine the relative mass transfer rates for $\mathrm{CO}_{2}$ and $\mathrm{O}_{2}$ in waters of various types. These experiments were also designed to confirm the theoretical relationship of $\mathrm{CO}_{2} / \mathrm{O}_{2}$. A nonlinear curve-fitting program is being used to reduce the data, but the analysis is not yet complete. Preliminary results indicate a noticeable decrease in the gas transfer rates of actively growing Gracilaria cultures. This is probably due to surface-active polysaccharides which are exuded by the plants. 
One benefit of aeration in seaweed culture tanks may be the elimination of diffusion barriers, which reportedly can develop around the macroalga held under stagnant conditions. Because the absorption of nutrients may be hindered by this phenomenon, the use of aeration may be critical when the seaweed is being pulse-fed. An experiment was conducted in which nitrogen uptake by nitrogen-starved Gracilaria was examined under various aeration regimes. The seaweed was soaked for 24 hours in seawater containing either high levels of nitrogen (no water exchange) or low levels of nitrogen (10 exchanges of seawater/day, ambient nitrogen at a level of $0.1 \mathrm{mg} / \mathrm{L}$ ). The high levels are similar to the nitrogen concentrations used during pulse feeding, and the low levels simulate the nitrogen concentrations to which the seaweed is exposed during its growth period.

As expected, it was found that nitrogen uptake (as determined by changes in plant nitrogen content) increases with increased aeration time. In addition, nitrogen uptake under all aeration regimes was greater in the high-nitrogen seawater than in the low-nitrogen seawater, indicating that water motion or agitation of the thallus is essential for the uptake of nutrients present in low concentrations. Whether aeration was provided in the day or night did not seem to affect nitrogen uptake by Gracilaria.

These data indicate that the goal of pulse-fertilization (increasing total plant nitrogen content) can be achieved most rapidly by utilizing high seawater nitrogen concentrations and continuous aeration. In addition, the poor nitrogen uptake under low-nitrogen stagnant conditions indicates that Gracilaria may be susceptible to a nutrient limitation during a nonaerated growth period, especially if "luxury consumption" of the particular nutrient does not occur during fertilization.

Trade-offs between pumping costs, the cost of carbon addition, and the frequency and duration of aeration were also made. A preliminary analysis of pumping seawater to supply carbon naturally resulted in energy-fixed/energy-expended ratios of 11.2 for Gracilaria and 21.6 for Ulva.

An evaluation of the effect of $\mathrm{CO}_{2}$ enrichment on Ulva and Gracilaria yields was completed during the past year. Oxygen production by Ulva was determined to be a function of alkalinity (carbon concentration) and $\mathrm{pH}$. Photosynthesis remains relatively constant within the range of $\mathrm{pH}$ tested $(7.5-9.5)$ but increases significantly with increasing alkalinity. Oxygen production by Gracilaria was determined to be a function of $\mathrm{pH}, \mathrm{CO}_{2}$, and the total alkalinity. At a constant $\mathrm{CO}_{2}$ concentration, photosynthesis increases uniformly as the $\mathrm{pH}$ is increased. This suggests that Gracilaria photosynthesis correlates poorly with $\mathrm{CO}_{2}$ concentration and may indeed correlate with biocarbonate or total carbon concentration. The conclusion is that Gracilaria is more adversely affected by low alkalinity than Ulva. Gracilaria photosynthesis also declines more precipitously at high $\mathrm{pH}$ than does Ulva photosynthesis (see Figure 2-5). Higher photosynthetic rates at higher $\mathrm{pH}$ levels and lower alkalinities would be of significant advantage in the culture of macroalgae. It is advantageous to grow macroalgae which flourish at higher $\mathrm{pH}$ levels and lower alkalinities.

A screening activity was undertaken to examine macroalgae as a potential source of petroleum replacement products. Initial results indicate that macroalgae produce very low quantities of lipids, ranging from $1 \%$ to $5 \%$ of the total organic weight. The majority are polar, membrane-bound lipids (Table 2-3), which are less valuable as fuels.

Emergents. Research on emergent aquatics was begun by SERI in 1980, when a subcontract was let to the University of Minnesota to investigate the use of wetlands to 


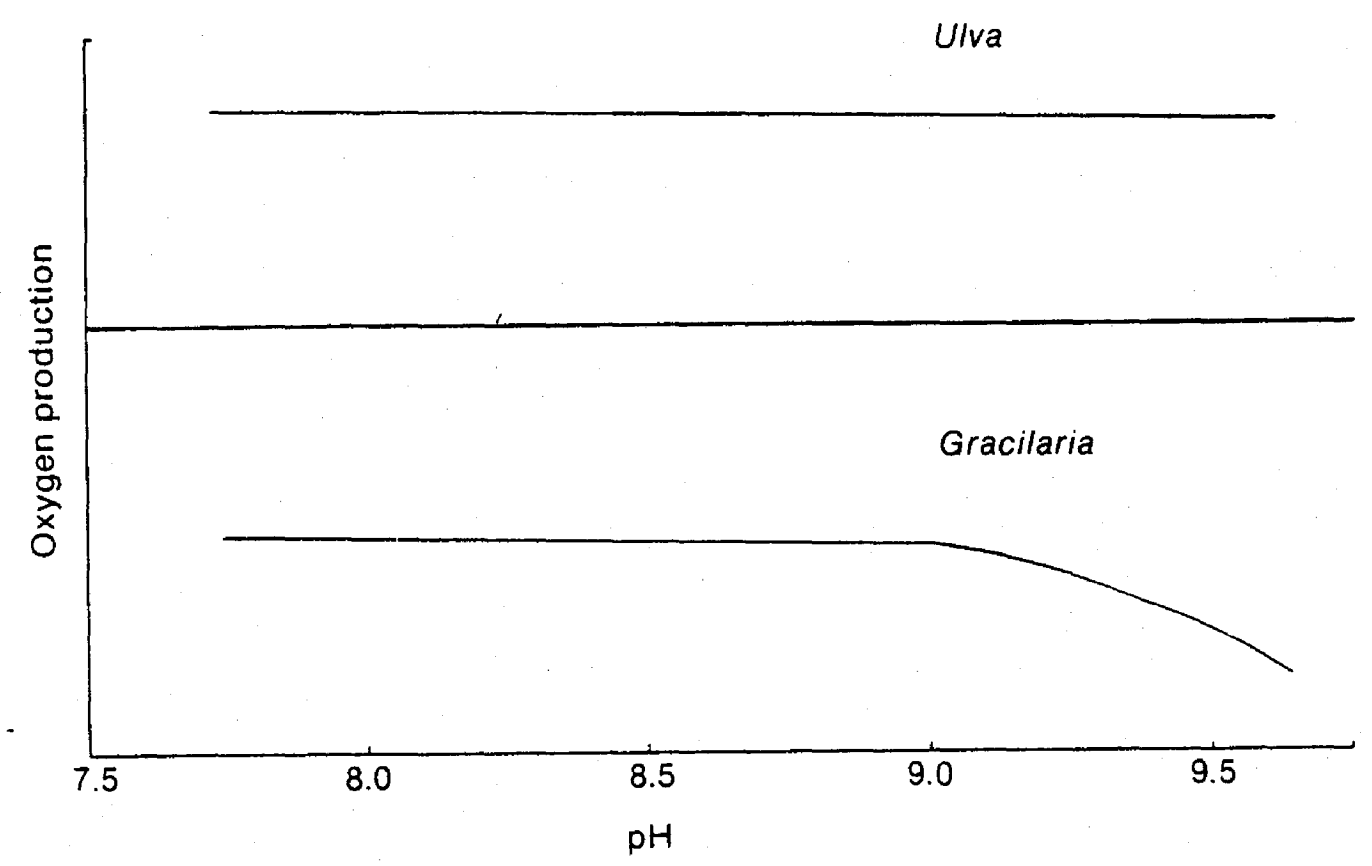

Figure 2-5. Relative Oxygen Production vs. $\mathrm{pH}(\mathrm{TIC}=0.5 \mathrm{mM})$

produce biomass energy crops. Wetlands dominated by Typha (cattails) and other emergent vegetation, such as Phragmites (reeds) and Scripus (rushes), are among the most productive systems in the temperate zone. Minnesota, with over 2 million hectares of available peatland and 1.4 million additional hectares of available wet mineral soils, appears to have considerable potential for wetland crop production. Among the attractive features of this system is the fact that wetland crops would not compete with traditional crops for prime agricultural land. The use of peatlands for the production of a renewable resource also offers an attractive alternative to peat mining.

The Minnesota research effort has demonstrated that total annual biomass yields between 20 and 30 dry tons/hectare are possible in planted stands. This compares with yields of total plant material between 9 and 16 dry tons/hectare in a typical Minnesota corn field. At least $50 \%$ of the Typha plant is composed of a below-ground rhizome system containing $40 \%$ starch and sugar, making rhizomes an attractive feedstock for alcohol production.

The major activity during 1983 was to conduct field trials to compare the effects of fertilization rates, planting densities, water management, and age of the establishment on yields of Typha. Biomass production was always superior in the second-year stands. In July 1982, the total biomass was $5 \mathrm{~g} / \mathrm{m}^{2}$; in July 1983 , the biomass was $652 \mathrm{~g} / \mathrm{m}^{2}$.

Nutrient levels were monitored to indicate which nutrients were limiting. Analysis of harvest data and tissue nutrient concentrations from field fertilization studies showed a large yield increase of $188 \%$, while tissue nitrogen increased by only $7 \%$ and tissue phosphorus by only $39 \%$. This supports the general conclusion from first-year results (when fertilizer was used) that nutrients were not the limiting growth factor in that year. No fertilizer was used in the second year. 
Table 2-3. Lipid Composition of Selected Macrophytes

\begin{tabular}{|c|c|c|c|c|c|c|}
\hline \multirow{2}{*}{ Species } & \multicolumn{6}{|c|}{$\begin{array}{l}\text { Lipid Fraction } \\
\text { (\%) }\end{array}$} \\
\hline & $\begin{array}{c}\text { Lipid } \\
\text { (\% dry } w t)\end{array}$ & Hydrocarbons & Isoprenoids & Triglycerides & Glycolipids & Phospholipids \\
\hline \multicolumn{7}{|l|}{ Gracilaria } \\
\hline $\begin{array}{l}\text { Nitrogen } \\
\text { enriched }\end{array}$ & 1.8 & 0.8 & 1.3 & 18.3 & 46.0 & 33.5 \\
\hline $\begin{array}{l}\text { Nitrogen } \\
\text { starved }\end{array}$ & 0.8 & 0.3 & 1.9 & 4.8 & 62.3 & 30.8 \\
\hline Ascophyllum & 4.5 & 0.3 & 15.7 & 15.4 & 50.0 & 19.5 \\
\hline Sargassum & 4.6 & 0.4 & 1.5 & 1.0 & 74.3 & 22.8 \\
\hline Caulerpa & 5.2 & 0.1 & - & - & - & - \\
\hline
\end{tabular}


Ash content has also been determined for tissue samples from all field experiments, because it is an important factor in biomass conversion. Typha grown on mineral soils exhibited mean ash contents of $6.5 \%$ to $7.4 \%$, while Typha grown on organic soils had a mean ash content of $5.2 \%$. Potassium is one of the more prevalent nutrients in Typha samples; the level of applied potassium fertilizer was found to significantly affect the ash content of the plant tissue. The variability in ash content resulting from soil types and nutrient application may significantly affect plant growth and development, as well as biomass conversion.

Analysis of plant material from the nutrient uptake studies showed that, on the average, $65 \%$ of the plant potassium and $76 \%$ of the plant phosphorus were located in the belowground tissue by late October. This trend-translocation of nutrients from above to below ground (as the season progresses)-is similar to that observed for tissue nitrogen. It could have significant impact on production scenarios, including aspects such as the time of harvest, amount of below-ground harvest, and long-term fertilization reauirements. At the very least, the simultaneous maximum uptakes of the three macronutrients suggests the possibility of a single, timed fertilizer application. Also, two-year yield and nutrient usage studies show that Typha stands utilize nutrients more efficiently af ter the establishment year, a promising trend for efficient biomass production.

Microalgae. The objective of this activity is to conduct a comprehensive screening activity that will identify the best microalgae strains for energy production. The strategy for this activity is illustrated in Figure 2-6 and 2-7. As a first level activity, microalgae species are collected and characterized for growth. The most rapidly growing species are then characterized for lipid content. As a final test for first level screening they are grown in outdoor culture. Species that have the best characteristics are passed to the second level of testing for detailed characterization and species improvement. Emphasis has been on collecting species from the California and Nevada deserts. (See Figure 2-8 for map of locations sampled.)

The collection, isolation, and analysis of individual algae species found in the desert was conducted from a mobile field laboratory. This laboratory allowed for the collection and preliminary growth estimations of various algae from numerous desert locations. Isolation of algal species into monocultures allowed detailed analysis of the yields, efficiencies, and proximate composition of each species. In addition, water samples were analyzed to identify major inorganic chemical constituents. These studies provided basic information on marine and desert algae and on the aquatic environment in the desert which can be applied to any installation in which saline water may be used.

During 1983, 58 microalgae were isolated from California and Nevada desert areas and grown in unialgal cultures (Table 2-4). Determination of the best nitrogen source and estimation of rough yields and efficiencies were made for some of desert the isolates. Yields and chemical composition were determined for five species or strains of desert microalgae (see Table 2-5).

Of importance in determining the suitability of a species for culture is its growth response to environmental variation. Responses to temperature and salinity variation of selected desert microalgae, as determined by salinity-temperature gradient analysis, is given in Table $2-6$.

Of the species collected and characterized, the Ankistrodesmus falcatus from Pyramid Lake in Nevada has seemed most promising and is now being fully characterized for lipids and growth in outdoor facilities. Growth of the species is exceptional over a wide range 


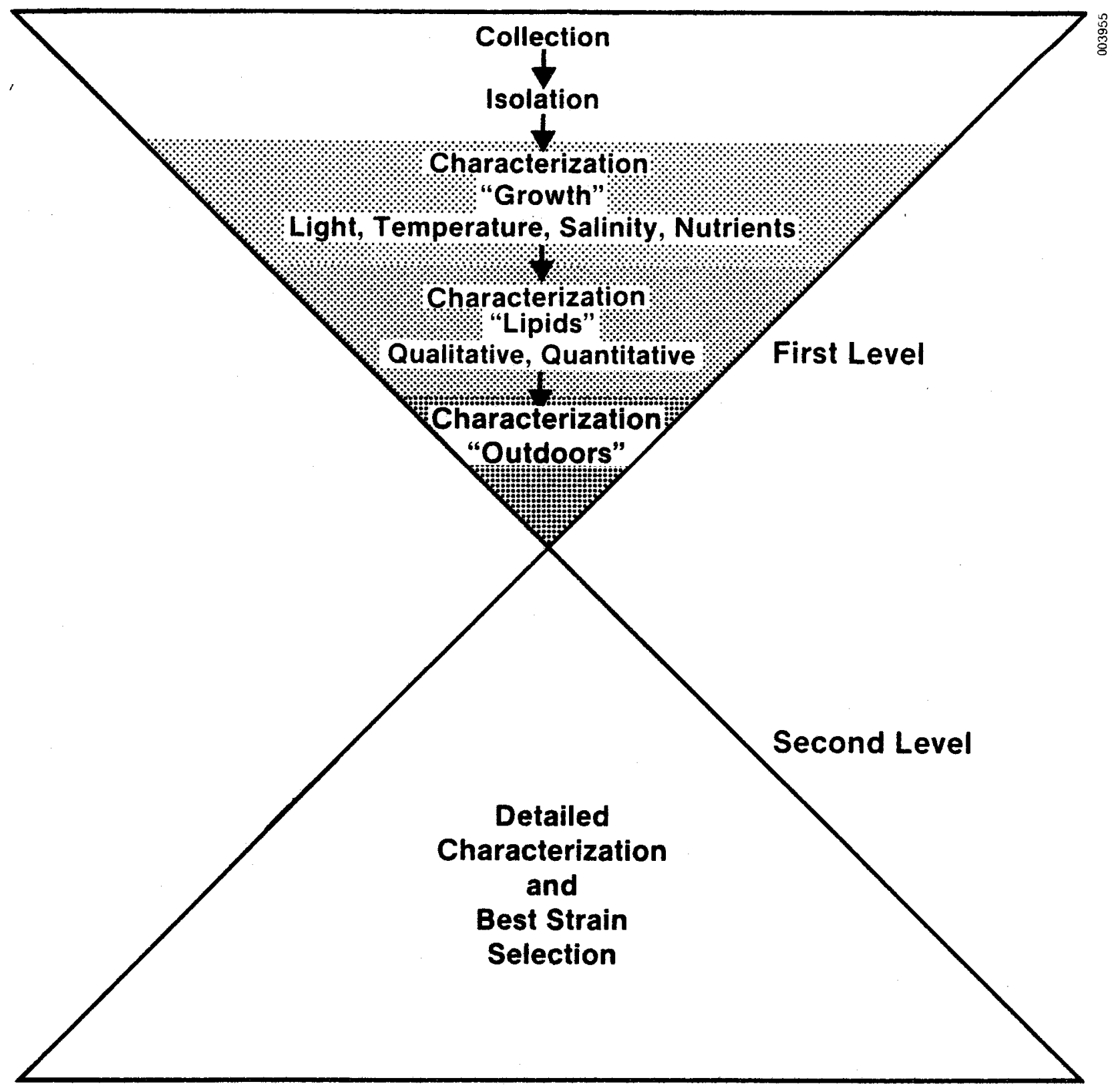

Figure 2-6. Schematic of Strategy for Comprehensive Sereening of Microalgae Strains 


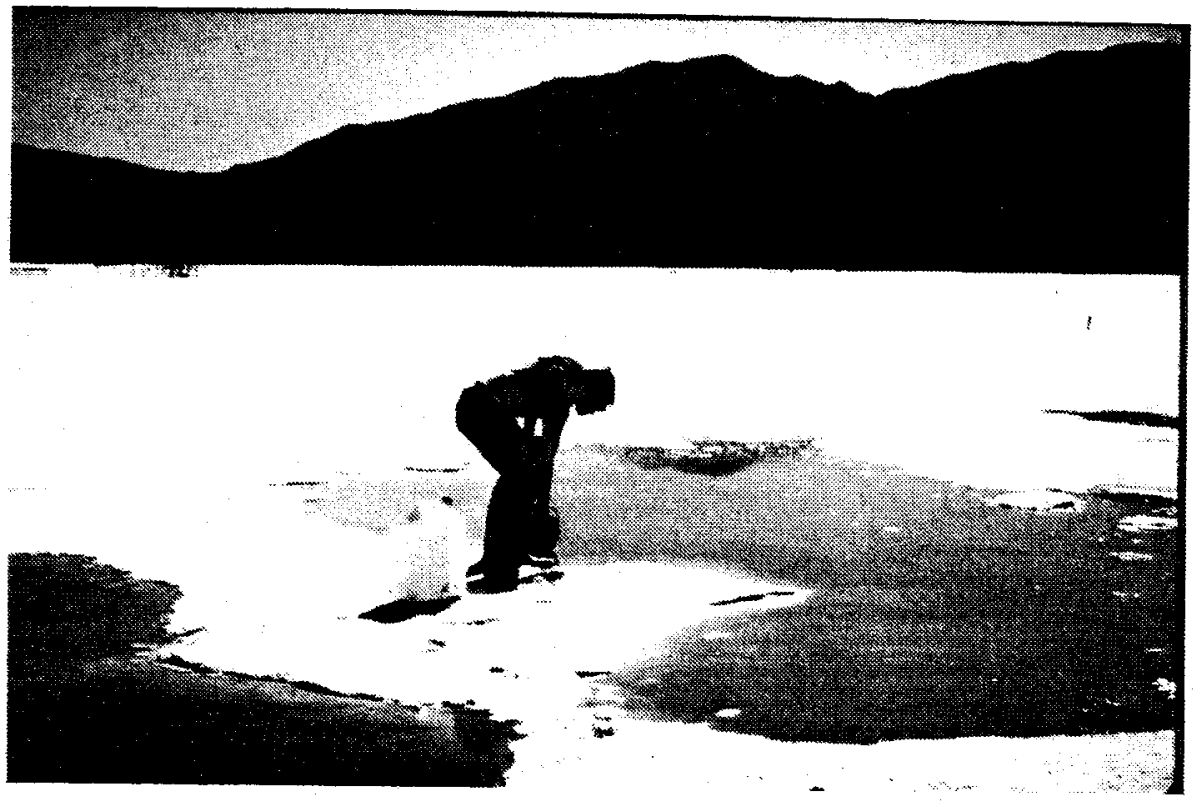

Figure 2-7a. Collection of Microalgae from Saline Desert Regions

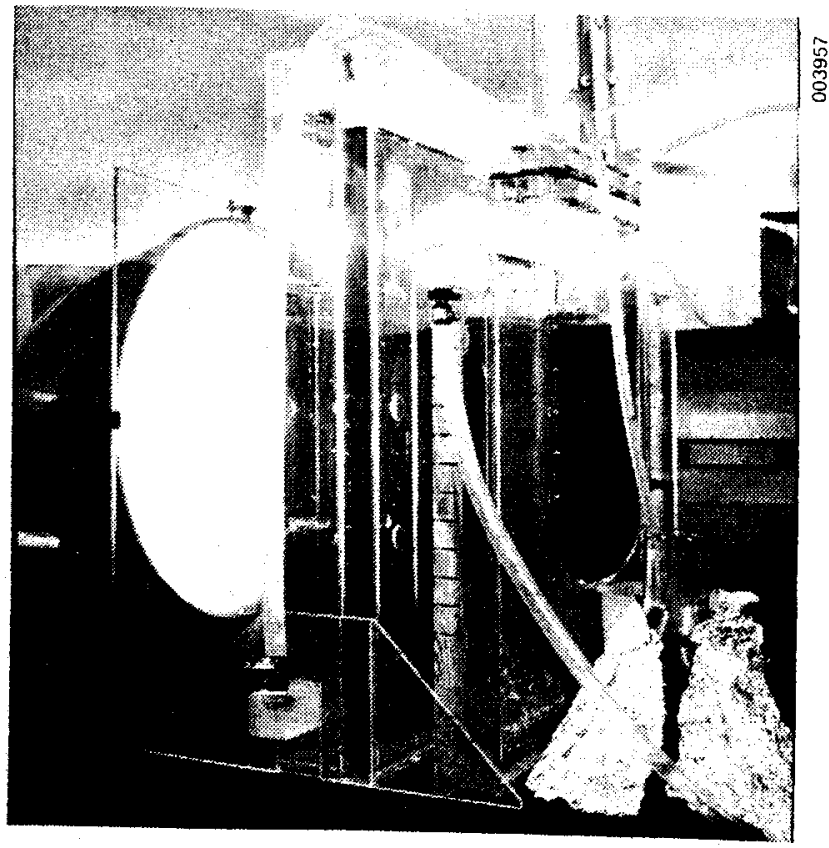

Figure 2-7b. Growth Studies of Selected Species Using Chemostats 


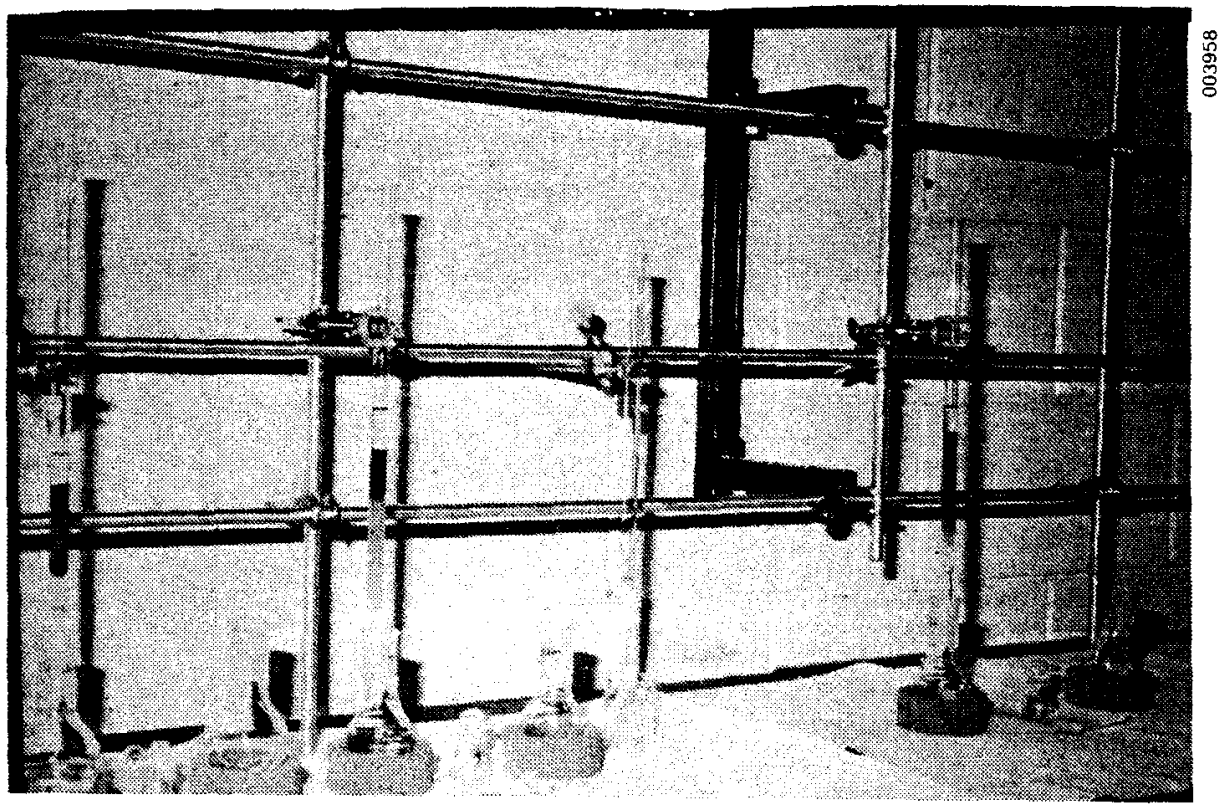

Figure 2-7c. Studies of the Lipid Fractions Produced by the Microalgae

of salinities, temperatures, and nutrients (see Figures 2-9 and 2-10). From the response curve it is evident that best growth occurrs between $5-7 \mathrm{~g} / \mathrm{L}$ and $16-26^{\circ} \mathrm{C}$. It grows well at a high biomass density and has a high lipid content.

The second step in screening is the determination and quantification of the chemical composition of selected microalgae grown under different conditions. This analysis is an important aspect of the screening process. This activity is primarily carried out at the Georgia Institute of Technology. Chemical analyses are carried out in accordance with a standard procedure set up by the program.

Microalgal lipids are typically esters of glycerol and fatty acids having carbon numbers in the range of $\mathrm{C}_{12}-\mathrm{C}_{20^{\circ}}$. Lipids can be subdivided according to their polarity, which depends on the nonpolar (lipophilic) carbon chains (fatty acids, long-chain alcohols) and on the polar (hydrophilic) moieties, such as phosphate and carboxylic groups, alcohols, sugar, or bases in each lipid. Nonpolar lipids (neutral lipids) are triglycerides, free fatty acids, hydrocarbons, and wax esters (only a few algae). The polar lipids are acyl lipids and mainly consist of phospholipids and glycolipids. The main phospholipids of algae are phosphatidyl choline (PC), phosphatidyl glycerol (PG), phosphatidic acid (PA), and diphosphatidyl glycerol (cardiolipin, DPG). The major algal glycolipids are monogalactosyl diglyceride (MGDG), digalactosyl diglyceride (DGDG), and sulphoquinovosyl diglyceride (sulpholipid, SL). A novel class of algal lipids are chlorosulpholipids which are derivatives of $\mathrm{N}$-docosane-1,14-diol and of $\mathrm{N}$-tetracosane-1,15-diol disulphates and which have been found in Chrysophyta and Cyanophyta. 


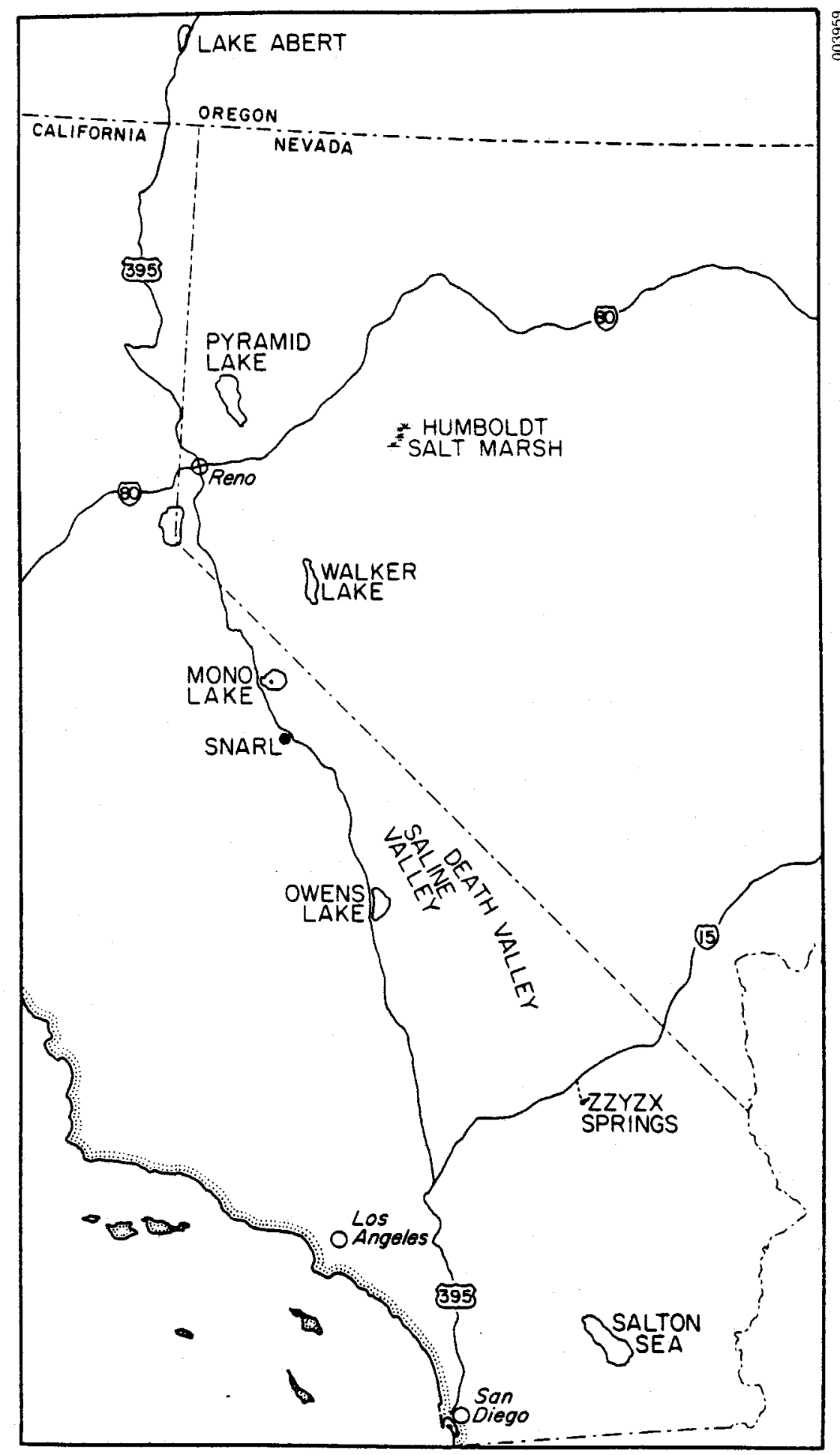

Figure 2-8. General Locations of Areas Sampled in the Desert of Eastern California and Western Nevada 
Table 2-4. Cultures of Desert Algae Isolated and Maintained by the Seripps Project in FY 1983

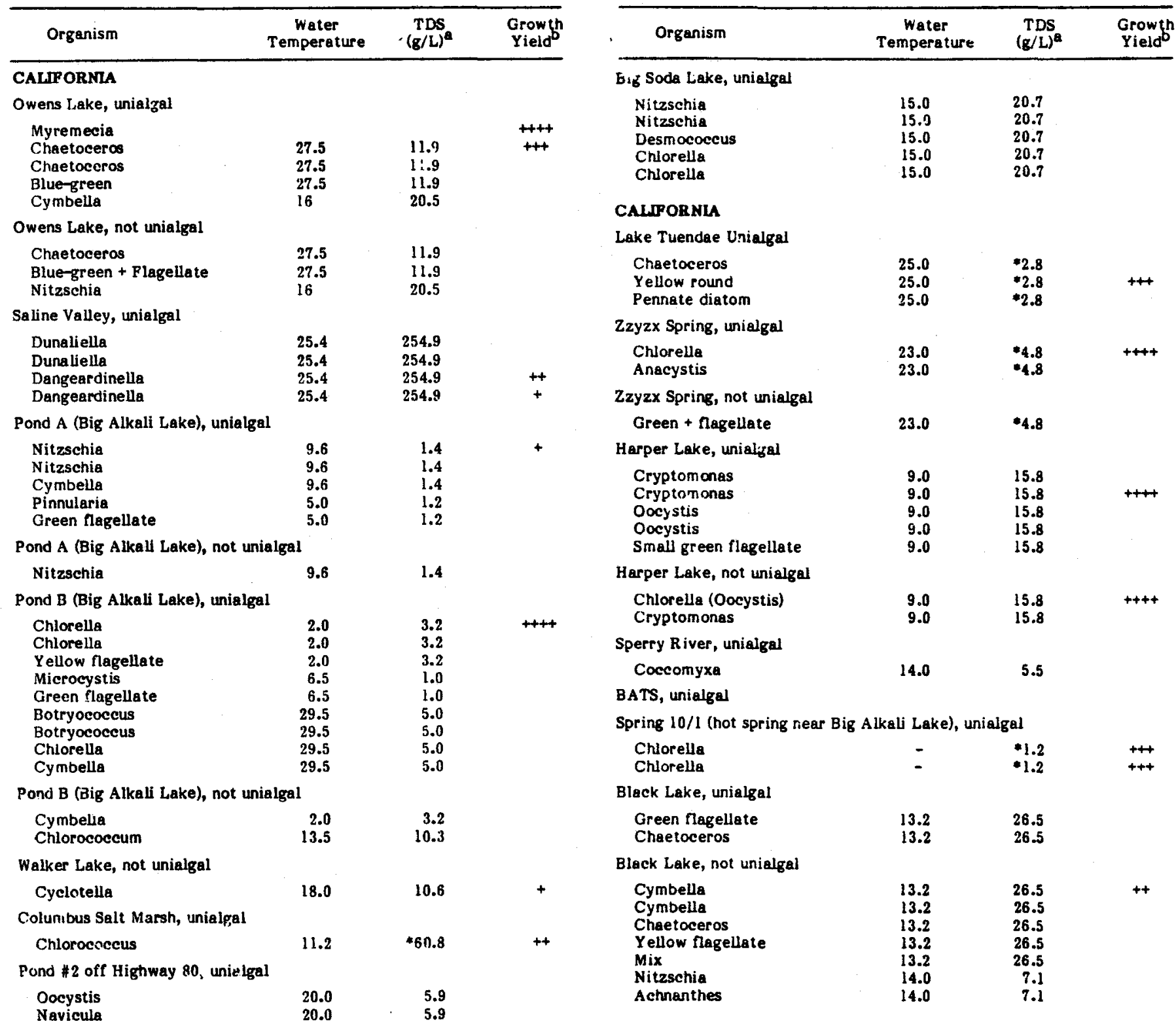


Table 2-4. Cultures of Desert Algae Isolated and Maintained by the Seripps Project in FY 1983 (Concluded)

\begin{tabular}{|c|c|c|c|}
\hline Organism & $\begin{array}{c}\text { Water } \\
\text { Temperature }\end{array}$ & $\begin{array}{c}\operatorname{TDS} \\
(\mathrm{g} / \mathrm{L})^{\mathrm{a}}\end{array}$ & $\begin{array}{l}\text { Growth } \\
\text { Yield }\end{array}$ \\
\hline \multicolumn{4}{|l|}{ NEVADA } \\
\hline \multicolumn{4}{|l|}{ Pyramid Lake, unialgal } \\
\hline $\begin{array}{l}\text { Anacystis } \\
\text { Nannochloris } \\
\text { Ankistrodesmus Falcatus } \\
\text { Synechococcus } \\
\text { Nitzschia } \\
\text { Green flagellate } \\
\text { Green ovoid }\end{array}$ & $\begin{array}{l}17.4 \\
17.4 \\
17.4 \\
15.0 \\
15.0 \\
15.0 \\
15.0\end{array}$ & $\begin{array}{l}4.9 \\
4.9 \\
4.9 \\
4.7 \\
4.7 \\
4.7 \\
4.7\end{array}$ & $\stackrel{t+2}{+++t}$ \\
\hline \multicolumn{4}{|l|}{ Pyramid Lake, not unialgal } \\
\hline $\begin{array}{l}\text { Nannochloris } \\
\text { Nannochloris } \\
\text { Yellow round } \\
\text { Green round } \\
\text { Coccoid green }\end{array}$ & $\begin{array}{l}17.4 \\
17.4 \\
17.4 \\
15.0 \\
15.0\end{array}$ & $\begin{array}{l}4.9 \\
4.9 \\
4.9 \\
4.7 \\
4.7\end{array}$ & $\stackrel{+}{++++}+$ \\
\hline \multicolumn{4}{|l|}{ Walker Lake, unialgal } \\
\hline $\begin{array}{l}\text { Cyclotella } \\
\text { Anacystis } \\
\text { Oocystis } \\
\text { Nannochloris } \\
\text { Nannochloris } \\
\text { Yellow-green flagellate } \\
\text { Yellow-green flagellate } \\
\text { Green ovoid } \\
\text { Green flagellate } \\
\text { Nitzschia } \\
\text { Nannochloris } \\
\text { Desmococcus } \\
\text { Cyclotella } \\
\text { Chiorella } \\
\text { Cosmarium } \\
\text { Anacystis }\end{array}$ & $\begin{array}{l}18.0 \\
18.0 \\
18.0 \\
18.0 \\
18.0 \\
18.0 \\
18.0 \\
13.5 \\
13.5 \\
13.5 \\
13.5 \\
13.5 \\
13.5 \\
13.5 \\
24.0 \\
24.0\end{array}$ & $\begin{array}{l}10.6 \\
10.6 \\
10.6 \\
10.6 \\
10.6 \\
10.6 \\
10.6 \\
10.3 \\
10.3 \\
10.3 \\
10.3 \\
10.3 \\
10.3 \\
10.3 \\
4.7 \\
44.7\end{array}$ & $\begin{array}{c}++ \\
++++ \\
+++ \\
++++ \\
++++ \\
++ \\
++\end{array}$ \\
\hline \multicolumn{4}{|l|}{ BATS, not unialgla } \\
\hline Chaetoceros & 24.0 & $\bullet 4.7$ & \\
\hline \multicolumn{4}{|l|}{ Armagosa River, uniaigla } \\
\hline $\begin{array}{l}\text { Green flagellate } \\
\text { Nitzschia sigmoida } \\
\text { Nitzschia }\end{array}$ & $\begin{array}{r}8.4 \\
24.0 \\
24.0\end{array}$ & $\begin{array}{l}8.4 \\
2.2 \\
2.2\end{array}$ & \\
\hline \multicolumn{4}{|c|}{ MISCRLLAANEOUS CALTPORNIA CULTURES } \\
\hline \multicolumn{4}{|l|}{ Salton Sea, uniaigal } \\
\hline $\begin{array}{l}\text { Chaetoceros } \\
\text { Dunalietla } \\
\text { Nitzschia } \\
\text { Flagellate (agar) } \\
\text { Pennate (agar) } \\
\text { Flagellate }\end{array}$ & $\begin{array}{l}20.7 \\
20.7 \\
20.7 \\
20.7 \\
20.7 \\
20.7\end{array}$ & $\begin{array}{l}39.0 \\
39.0 \\
39.0 \\
39.0 \\
39.0 \\
39.0\end{array}$ & $\stackrel{d}{+++}+$ \\
\hline \multicolumn{4}{|l|}{ Salton Sea, not unialgal } \\
\hline $\begin{array}{l}\text { Navicula + green alga } \\
\text { Green colony }\end{array}$ & $\begin{array}{l}20.7 \\
20.7\end{array}$ & $\begin{array}{l}39.0 \\
39.0\end{array}$ & \\
\hline \multicolumn{4}{|l|}{ Mono Lake, unialgal } \\
\hline $\begin{array}{l}\text { Nitzschia } \\
\text { Coecomyxa }\end{array}$ & & $\begin{array}{c}\text { hen } \\
++++ \\
+++\end{array}$ & \\
\hline
\end{tabular}

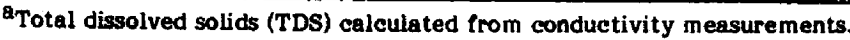

${ }^{b}$ Growth yield estimated visually by one person for all cultures. 
Table 2-5. Yields and Proximate Cellular Chemistry of Selected Desert Microalgae

\begin{tabular}{lcccc}
\hline \multicolumn{1}{c}{ Isolate and Origin } & $\begin{array}{c}\text { Yield } \\
\left(\mathrm{g} / \mathrm{m}^{2} \text { day) }\right.\end{array}$ & $\begin{array}{c}\text { Lipid } \\
(\%)\end{array}$ & $\begin{array}{c}\text { Carbohydrate } \\
(\%)\end{array}$ & $\begin{array}{c}\text { Protein } \\
(\%)\end{array}$ \\
\hline Ankistrodesmus (Pyramid Lake) & 11.5 & 31 & 24 & 36 \\
\hline Nitzschia (Mono Lake) & 21.6 & 22 & 14 & 36 \\
Oocystis (Walker Lake) & $40^{\mathrm{a}}$ & 10.5 & 37 & 39 \\
Chlorella (Pond B) & 13.9 & 18 & - & 68 \\
Chlorella (Zzyzx) & 13.2 & 21 & 24 & 55 \\
\hline
\end{tabular}

${ }^{a}$ This yield experiment is being repeated.

Table 2-6. Responses of Some Saline Desert Algae to Temperature and Salinity

\begin{tabular}{|c|c|c|c|c|c|c|}
\hline \multirow[b]{2}{*}{$\begin{array}{c}\text { Isolate } \\
\text { (and Origin) }\end{array}$} & \multicolumn{3}{|c|}{ Temperature $\left({ }^{\circ} \mathrm{C}\right)$} & \multicolumn{3}{|c|}{ Salinity $(g / L)$} \\
\hline & $\begin{array}{l}\text { For Best } \\
\text { Growth }\end{array}$ & $\begin{array}{l}\text { Range } \\
\text { for Some } \\
\text { Growth }\end{array}$ & $\begin{array}{l}\text { Little } \\
\text { or No } \\
\text { Growth }\end{array}$ & $\begin{array}{l}\text { For Best } \\
\text { Growth }\end{array}$ & $\begin{array}{l}\text { Range } \\
\text { for Some } \\
\text { Growth }\end{array}$ & $\begin{array}{l}\text { Little } \\
\text { or No } \\
\text { Growth }\end{array}$ \\
\hline$\frac{\text { Nitzschia }}{\text { (Mono Lake) }}$ & $30-36$ & $15-36$ & $10,41-44$ & $50-70$ & $28-86$ & 9,120 \\
\hline$\frac{\text { Ankistrodesmus }}{\text { (Pyramid Lake) }}$ & 26 & $21-30$ & $11-16,35$ & 5.8 & $0.6-3$ & 8,11 \\
\hline$\frac{\text { Oocystis }}{\text { (Walker Lake) }}$ & $20-25$ & $16-33$ & 11 & 18 & $6.8-24$ & 1.2 \\
\hline$\frac{\text { Chlorella }}{(\mathrm{Zzyzx})}$ & 25 & $15-30$ & 9,34 & 12 & $3-12$ & 一 \\
\hline$\frac{\text { Cryptomonas }}{\text { (Harper Lake) }}$ & $16-30$ & $11-35$ & - & 36 & $2-36$ & - \\
\hline$\frac{\text { Dangeardinella }}{\text { (Saline Valley) }}$ & $30-35$ & $21-35$ & 10,16 & 266 & 206 & $27-146$ \\
\hline
\end{tabular}




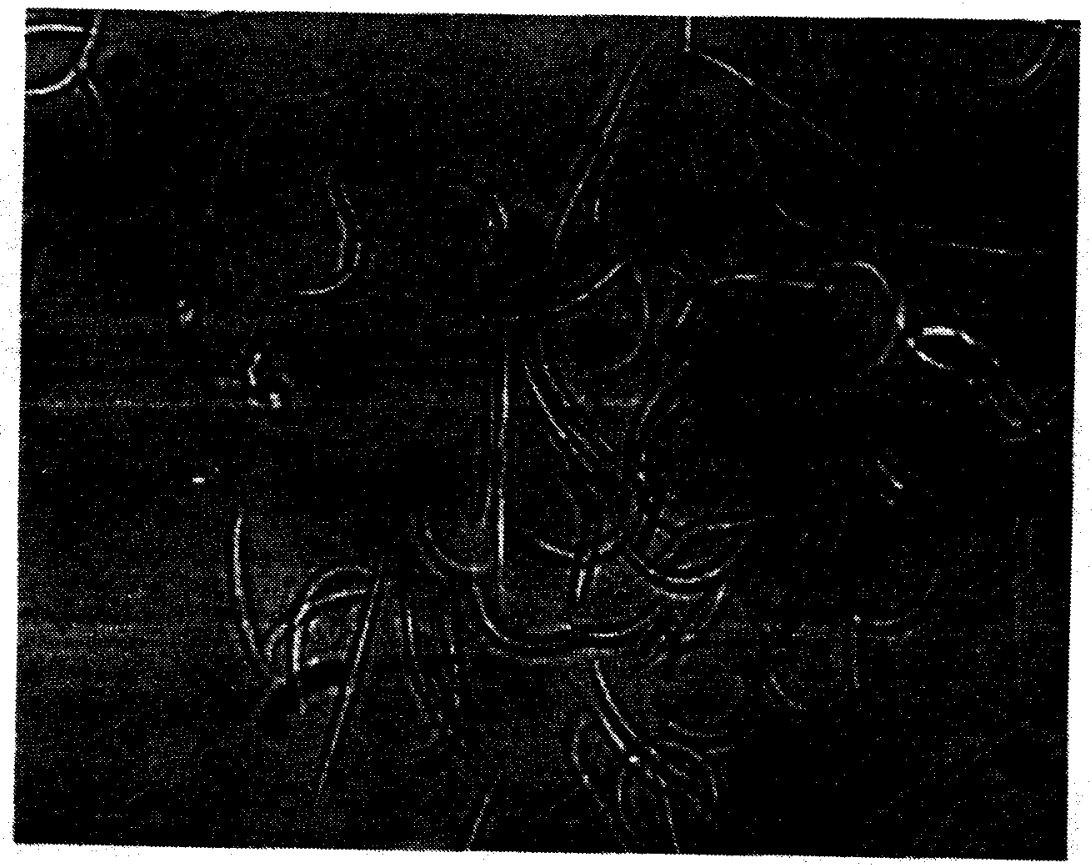

Figure 2-9a. Ankistrodesmus falcatus Isolated from Pyramid Lake

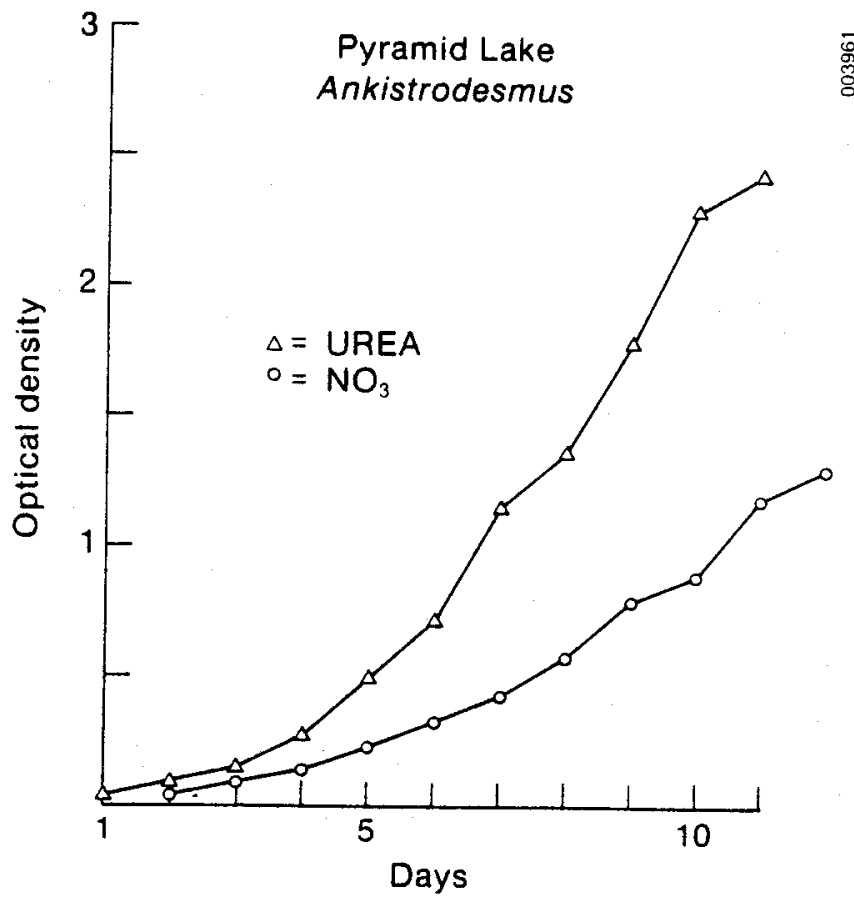

Figure 2-9b. Increases in Optical Density of Pyramid Lake Ankistrodesmus Cultures
Grown on Nitrate and Urea 


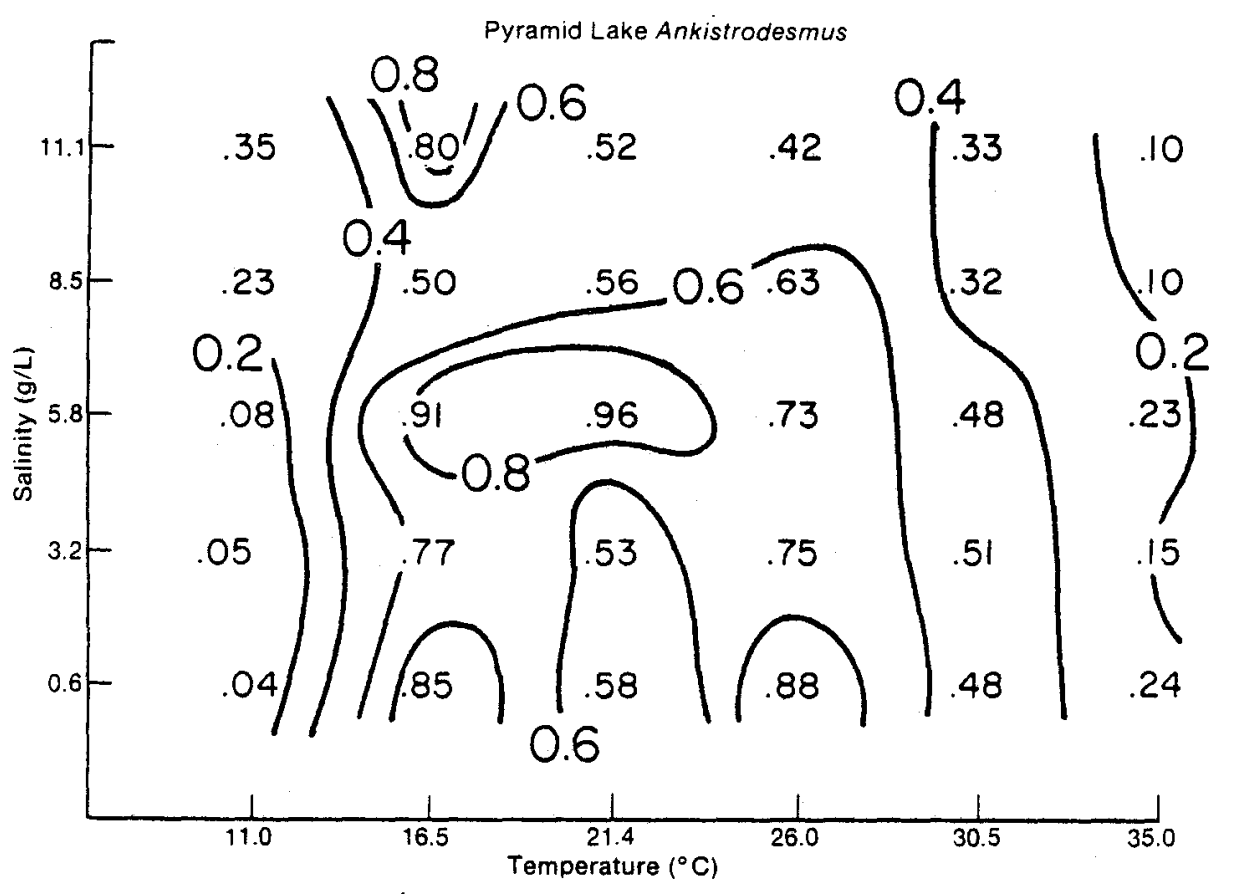

Figure 2-10. Growth Curve of Ankistrodesmus Showing Response to Salinity and Temperature

The proximate chemical composition of seven species of freshwaster, desert, and marine unicellular eukaryotic microalgae grown under controlled conditions was measured. Emphasis was placed on the analysis of lipids (Table 2-7). Ankistrodesmus, Dunaliella spp., Isochrysis, Nannochloris, and Nitzschia contained an average of $30 \%$ protein, $15 \%$ carbohydrate, and 25\% lipid (the percentages are percentages of organic cell weight). Botryococcus braunii contained about $45 \%$ lipid. The effects of culture conditions on the proximate chemical composition of Botryococcus braunii, Dunaliella salina, and Isochrysis in nitrogen-deficient medium were a decrease in protein content and an increase in carbohydrate content; of Dunaliella salina, a decrease in lipids; and of Isochrysis, an increase in lipid content. Cultivation of Dunaliella salina in medium with an increased concentration of sodium chloride induced the accumulation of osmotic glycerol with minimal effect on the other constituents. In Botryococcus and Isochrysis, sodium stress was mainly expressed by reduced protein content.

Lipids may be divided into various classes of compounds, according to the polarity. Neutral lipids and triglycerides (fatty acids) are considered to have the most potential as fuels. Microalgae produce a variety of lipids, and the proportions of lipids change with growth conditions. (Table 2-8 shows the lipid concentrations for several species under different growth conditions.) The relative proportion of neutral lipids in Botryococcus braunii, Isochrysis sp., and a nitrogen-deficient culture Dunaliella bardawil was high, with multiply branched hydrocarbons predominating. The concentrations of the polar glycolipids and phospholipids in all species investigated were fairly typical of photosynthetic eukaryotic algae in general. The fatty acid compositions were species-specific with changes occurring in the relative frequencies of individual acid chains of cells cultivated under different conditions and growth phases. All species synthesized Cl4:0, C16:0,

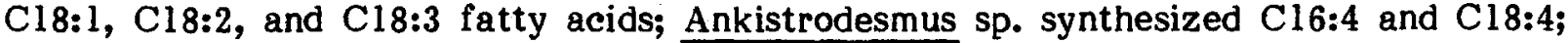
Isochrysis sp., C18:4 and C22:6; Nannochloris sp., C16:2, C16:3, and C20:5; and Nitzschia, $\mathrm{Cl} 6: 2, \mathrm{Cl} 6: 3$, and $\mathrm{C} 20: 5$. Nitrogen deficiency and salt stress induced the accumulation 
Table 2-7. Proximate Cellular Composition of Unicellular Algae Grown under Optimal, Nitrate-Deficient, or Salt Stress Conditions ${ }^{\mathbf{a}}$

\begin{tabular}{|c|c|c|c|c|c|c|c|}
\hline \multirow{2}{*}{ Species } & \multirow{2}{*}{$\begin{array}{c}\text { Growth } \\
\text { Conditions }\end{array}$} & \multirow{2}{*}{$\begin{array}{c}\% \text { Dry } \\
\text { Weight } \\
\text { Ash }\end{array}$} & \multicolumn{5}{|c|}{$\%$ Organic Weight } \\
\hline & & & Protein & Carbohydrate & Lipid & Glycerol & Unknown \\
\hline \multirow[t]{3}{*}{ Botryococcus braunii } & FW, NE & 5.6 & 22.0 & 14.1 . & 44.5 & 0.1 & 19.3 \\
\hline & FW, ND & 7.8 & 20.6 & 14.3 & 54.2 & 0.1 & 10.8 \\
\hline & $0.5 \mathrm{M} \mathrm{NaCl}, \mathrm{NE}$ & 59.6 & 15.0 & 13.3 & 46.3 & 0.1 & 25.3 \\
\hline Dunaliella bardawil & $2 \mathrm{M} \mathrm{NaCl}, \mathrm{ND}$ & 14.7 & 9.7 & 40.4 & 10.4 & 16.4 & 23.1 \\
\hline \multirow[t]{3}{*}{ Dunaliella salina } & $0.5 \mathrm{M} \mathrm{NaCl}, \mathrm{NE}$ & 8.6 & 29.3 & 16.3 & 25.3 & 9.4 & 19.7 \\
\hline & $0.5 \mathrm{M} \mathrm{NaCl}, \mathrm{ND}$ & 7.7 & 12.5 & 55.5 & 9.2 & 4.7 & 18.1 \\
\hline & $2 \mathrm{M} \mathrm{NaCl}, \mathrm{NE}$ & 21.7 & 35.9 & 12.5 & 18.5 & 27.7 & 5.4 \\
\hline Ankistrodesmus sp. & $\mathrm{FW}, \mathrm{NE}$ & 4.5 & 31.1 & 10.8 & 24.5 & 0.1 & 33.5 \\
\hline \multirow[t]{3}{*}{ Isochrysis sp. } & $0.5 \mathrm{M} \mathrm{NaCl}, \mathrm{NE}$ & 12.0 & 37.0 & 11.2 & 7.1 & 0.1 & 44.6 \\
\hline & $0.5 \mathrm{M} \mathrm{NaCl}, \mathrm{ND}$ & 52.0 & 23.3 & 20.5 & 26.0 & 0.1 & 30.1 \\
\hline & $1 \mathrm{M} \mathrm{NaCl}, \mathrm{NE}$ & 65.9 & 34.7 & 15.5 & 15.3 & 0.1 & 34.4 \\
\hline Nannochloris sp. & $\mathrm{FW}, \mathrm{NE}$ & 13.6 & 33.1 & 13.2 & 20.8 & 0.1 & 32.8 \\
\hline Nitzschia sp. & $1.4 \mathrm{M} \mathrm{Na}^{+}, \mathrm{NE}$ & 20.4 & 16.8 & 9.2 & 12.1 & 0.1 & 61.8 \\
\hline
\end{tabular}

$a^{a}$ Analyses of five different algal cultures of each species were conducted; statistical analysis showed no standard error greater than $10 \%$.

${ }^{b}$ F $=$ Freshwater, NE $=$ Nutrient enriched, ND $=$ Nutrient deficient. 
Table 2-8. Fractionation of Algal Lipids on Unisil Columns ${ }^{a}$.

\begin{tabular}{|c|c|c|c|c|c|c|}
\hline \multirow{2}{*}{ Species } & \multirow{2}{*}{$\begin{array}{c}\text { Growth } \\
\text { Conditions }\end{array}$} & \multicolumn{5}{|c|}{ \% Total Lipid Weight } \\
\hline & & Hydrocarbon & Isoprenoid & Triglyceride & Glycolipids & Phospholipids \\
\hline \multirow[t]{3}{*}{ Botryococcus braunii } & FW, NE & 4.6 & 51.4 & 4.5 & 30.0 & 9.4 \\
\hline & FW, ND & 14.9 & 52.7 & 3.4 & 21.6 & 7.4 \\
\hline & $0.5 \mathrm{M} \mathrm{NaCl}, \mathrm{NE}$ & 5.2 & 46.0 & 28.5 & 9.3 & 9.7 \\
\hline Dunaliella bardawil & $2 \mathrm{M} \mathrm{NaCl}, \mathrm{ND}$ & 0.1 & 49.9 & 14.8 & 24.1 & 10.8 \\
\hline \multirow[t]{3}{*}{ Dunaliella salina } & $0.5 \mathrm{M} \mathrm{NaCl}, \mathrm{NE}$ & 0.1 & 0.4 & 6.3 & 76.8 & 16.5 \\
\hline & $0.5 \mathrm{M} \mathrm{NaCl}, \mathrm{ND}$ & 0.1 & 24.8 & 20.6 & 31.7 & 22.8 \\
\hline & $2 \mathrm{M} \mathrm{NaCl}, \mathrm{NE}$ & 0.2 & 2.1 & 28.2 & 55.9 & 13.6 \\
\hline Ankistrodesmus sp. & $\mathrm{FW}, \mathrm{NE}$ & 0.7 & 1.8 & 39.6 & 40.9 & 17.0 \\
\hline \multirow[t]{3}{*}{ Isochrysis sp. } & $0.5 \mathrm{M} \mathrm{NaCl}, \mathrm{NE}$ & 1.4 & 27.4 & 32.1 & 26.3 & 12.6 \\
\hline & $0.5 \mathrm{M} \mathrm{NaCl}, \mathrm{ND}$ & 2.2 & 28.4 & 18.0 & 26.0 & 25.3 \\
\hline & $1 \mathrm{M} \mathrm{NaCl}, \mathrm{NE}$ & 1.4 & 23.6 & 13.6 & 43.0 & 18.4 \\
\hline Nannochlor is sp. & $\mathrm{FW}, \mathrm{NE}$ & 0.2 & .5 .9 & 32.5 & 35.9 & 25.5 \\
\hline Nitzschia sp. & $1.4 \mathrm{M} \mathrm{Na}^{+}, \mathrm{NE}$ & 0.2 & 1.7 & 51.2 & 22.0 & 24.6 \\
\hline \multicolumn{7}{|c|}{$\begin{array}{l}\text { a Proportions of lipid eluates were determined by gas-liquid chromatography for the hexane eluate and gravimetrically } \\
\text { for the others. }\end{array}$} \\
\hline
\end{tabular}


of C18:I in all treated species and to some extent $\mathrm{C} 20: 5$ in Botryococcus braunii. These data provide additional evidence for the concept of biochemical classification and its control by environmental factors. During 1984, additional species will be characterized chemically with an emphasis on understanding how environmental changes influence lipid composition.

In addition to screening activities at Scripps and Georgia Tech, species will be collected and characterized by researchers at Alabama A\&M (salt marsh species), the Solar Energy Research Institute (Colorado halophytic species), and Ben Gurion University in Israel (halotolerant species shown to be oil rich). A preliminary literature search provided the basis for selecting Isochrysis, Monallanthus, and Chlorella as species for further study. Culture conditions will be defined and sustainable outdoor yields will be determined.

Finally, in 1983, the need for a centralized microalgae culture collection was identified. During the next year a steering committee will select the most promising species for fuel production, and include them in a specialized culture collection. The purpose of this collection is to make a unique and specialized set of species and data available to all organizations wishing to research, develop, or apply the capabilities of oil-producing microalgae.

\subsubsection{Species Improvement: Microalgae}

Species improvement comprises three areas of research: (1) culture manipulation and (2) metabolic regulation to enhance lipid production, and (3) genetics to develop the most useful strains. The emphasis has been on establishing lipid triggers in various species of microalgae through culture manipulation. A lipid trigger is the mechanism by which the metabolism of a microalgal culture may be switched from a state of cell division to that of lipid accumulation or switched from synthesis of one lipid fraction to another. For example, preliminary results of culture manipulation of Isochrysis have shown a marginal shift to higher total lipid production and a dramatic shift (40\%) toward increased neutral lipid production. This result is significant because maximum production of higher-value products such as these neutral lipids is desirable.

Researchers at the Solar Energy Research Institute have investigated the photophysiological and metabolic response of a strain of Chlorella to nutrient deficiency. Their studies indicate that high rates of biomass production can be maintained for 5-7 days after severe nitrogen starvation, even though cell division stops during this period. Furthermore, during this stage of no reproductive growth, $80 \%-90 \%$ of the newly produced algal mass appears as intracellular storage oil and lipids (Figure 2-11). The algal cells are characterized by an increase in cell volume (Figure 2-12) and a great reduction in the complexity of their intracellular membrane structures. Isotope tracer studies indicated that the increase in lipids was due to a synthesis of triglycerides. During this switch in metabolism, the amount of carbon incorporated into the cell dropped $60 \%$.

New evidence suggests that nonlipoidal material is not converted to lipids during periods of darkness, as was previously believed. The apparent synthesis of lipid in the dark does not appear to be due to the conversion of nonlipoidal storage materials into lipid. Instead, respiration preferentially consumes nonlipoidal material, whereas lipids are nearly totally conserved. Net production of additional lipids can occur only under illumination. 


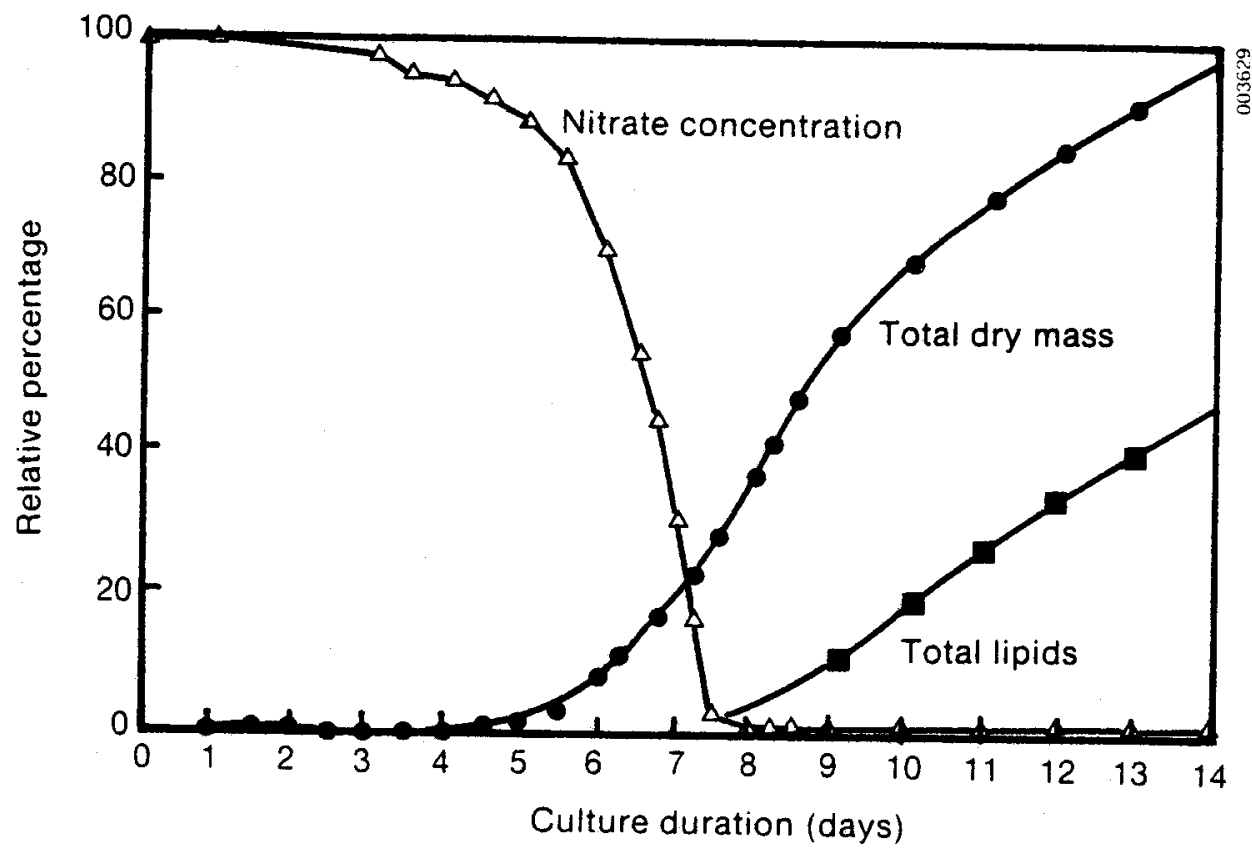

Figure 2-11. Physiological Responses of Chlorella Nitrogen-Limitation

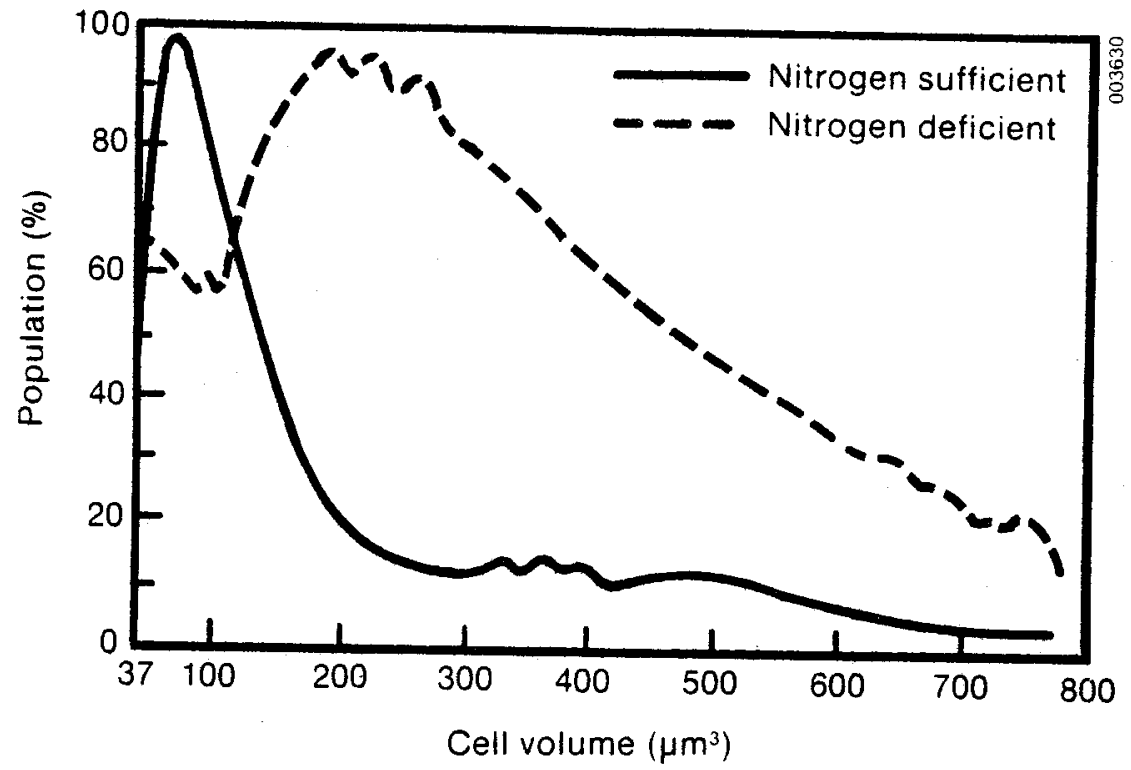

Figure 2-12. Changes in Cell Volume as a Result of Nitrogen Deprivation 
The Aquatic Species subprogram will continue to emphasize research on improving lipid yields through culture manipulation. Work is also being initiated to determine if, by the deregulation of various metabolic pathways, the yield of neutral lipids can be increased.

Researchers will also begin to isolate strains of species of microalgae that are promising. (Strains are genetic variants of the same species.) The physiological differences between strains of microalgae have been demonstrated to be as great as between species. At the University of Hawaii, strains of Phaeodactylum were tested for growth and lipid content. As shown in Table 2-9, different strains exhibited extreme differences in growth and lipid content response. Isolation of multiple strains of a promising species will allow development of a gene pool, which will be essential for future improvements through the application of genetics.

\subsubsection{Engineering Research and Development}

The objective of engineering research is to integrate biological concepts with engineering principles to develop a cost-effective microalgal culture technology. To accomplish this, engineering research is divided into three tasks: design coordination, component development, and experimental facilities.

\subsubsection{Design Coordination}

The objective of this subtask is to combine engineering criteria with biological perspectives to develop new approaches, novel systems, or design adaptations that stimulate research and development.

Jaycor, a subcontractor in the Aquatic Species subprogram is conducting systems analyses relating the complex interactions of a variety of physical, biological, and engineering variables, and comparing and evaluating system benefits and technical uncertainties. During the past year Jaycor reviewed the literature and summarized the existing microalgae technologies. This work led to the categorization of microalgal production designs into five basic concepts. The five basic concepts of production systems were organized according to the three most critical design factors: culture depth, mixing strategy, and enclosure configuration. The concepts are:

- Open bubbling systems

- Open pool circulation systems

- Deep open raceway cultivation systems

- Shallow open raceway cultivation systems

- Shallow closed raceway cultivation systems.

The extent of the diversity of design ideas has been documented in the publication Algal Mass Culture Technology Review of Patents. In addition, a technology review of microalgae harvesting technology was completed by Ben Gurion University.

A number of microalgal systems have been operated both commercially and experimentally during the past 30 years. Because of the variety of design approaches used in these systems, it is not possible to use one or two figures of merit (such as yield and 
Table 2-9. Comparison of Growth Responses and Lipid Content of Six Strains of Phaeodactylum

\begin{tabular}{|c|c|c|c|c|c|}
\hline \multirow{2}{*}{\multicolumn{2}{|c|}{ Strain }} & \multicolumn{3}{|c|}{ Relative Growth } & \multirow{2}{*}{ \% Lipic } \\
\hline & & $20^{\circ} \mathrm{C}$ & $25^{\circ} \mathrm{C}$ & $28^{\circ} \mathrm{C}$ & \\
\hline \multicolumn{2}{|c|}{ Scripps } & 0.70 & 0.30 & death & 21 \\
\hline Utex & $\begin{array}{r}640 \\
642 \\
646 \\
2089 \\
2050\end{array}$ & $\begin{array}{l}-\overline{75} \\
1.00 \\
0.95 \\
0.98\end{array}$ & $\begin{array}{l}0.45 \\
0.40 \\
0.45 \\
0.20 \\
0.45\end{array}$ & $\begin{array}{l}0.50 \\
0.35 \\
0.25 \\
0.25 \\
0.28\end{array}$ & $\begin{array}{l}- \\
- \\
10 \\
15\end{array}$ \\
\hline
\end{tabular}

product cost) for each system to determine which systems are best. None of the commercial systems were designed for low-cost production. Since they produce a high-value product-protein-few or no attempts have been made to minimize costs and maximize productivity. When producing fuels, costs must be minimized while maximizing productivity, if microalgal oils are to compete with petroleum products on the world market (Figure 2-13). It is possible to look at the operating characteristics along with the yields and costs for each system, observe the positive and negative aspects of each design, note problems common to all systems, and decide which systems or combinations of design factors are worth pursuing.

A mass culturing model was designed by Scientific Applications, Inc. (SAI), to provide an analytical tool for evaluating microalgal production systems, taking into account the effects of the complex interaction of the many biological, physical, chemical, and engineering factors involved in algae production, harvesting, and processing into final products. Essentially a process simulation model to describe the operations of a production facility, the model is designed with sufficient flexibility to describe and evaluate alternative cultivation designs and techniques. The production model has been coded and operated on the SERI computer system, and satisfactory correlations have been developed using the model to describe a thirty-day production cycle of the raceway at the University of Hawaii and production by the ponds operated by Microbial Products (see Section 2.3.2.2 for description of these systems).

\subsubsection{Experimental Facilities}

There are several reasons for establishing outdoor experimental mass culture facilities: (1) The performance of various systems can be compared. (2) Strategies for mass culture management can be developed. (3) Laboratory tests can be scaled up. (4) Laboratoryselected microalgae strains can be tested in outdoor mass culture. Presently SERI supports two experimental facilities: one is operated by the University of Hawaii, and the other by Microbial Products, Inc. (formerly EnBio, Inc.) in California. Figure 2-14 is a schematic of the raceway in Hawaii, and Figure 2-15 is a diagram of the pond system operated by Microbial Products. The two systems differ primarily in depth: the ponds are operated at $20 \mathrm{~cm}$ and the raceways at $10 \mathrm{~cm}$. The mixer types, harvesting methods, and media salinities also differ. 


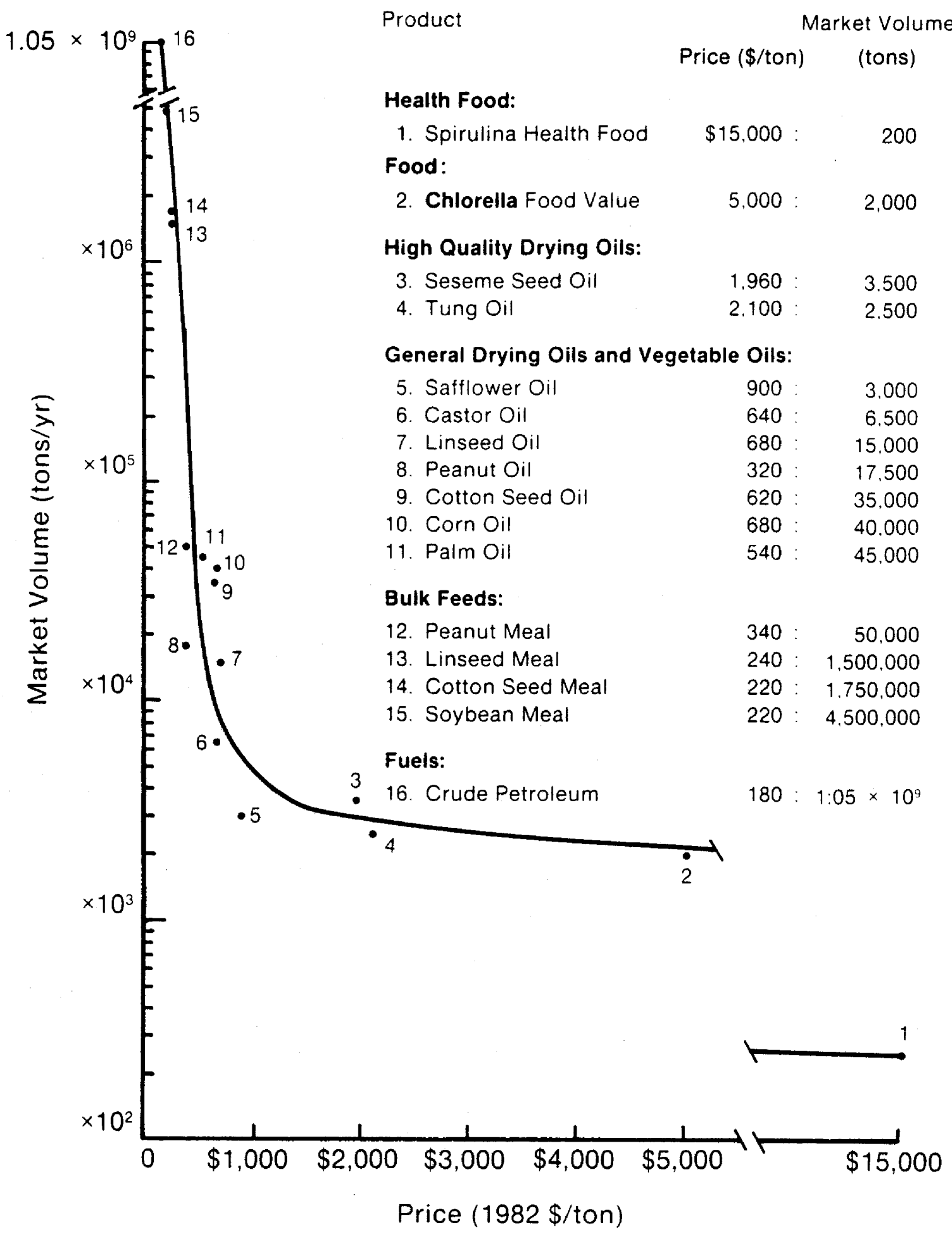

Figure 2-13. Cost of Production Versus Market Volume 


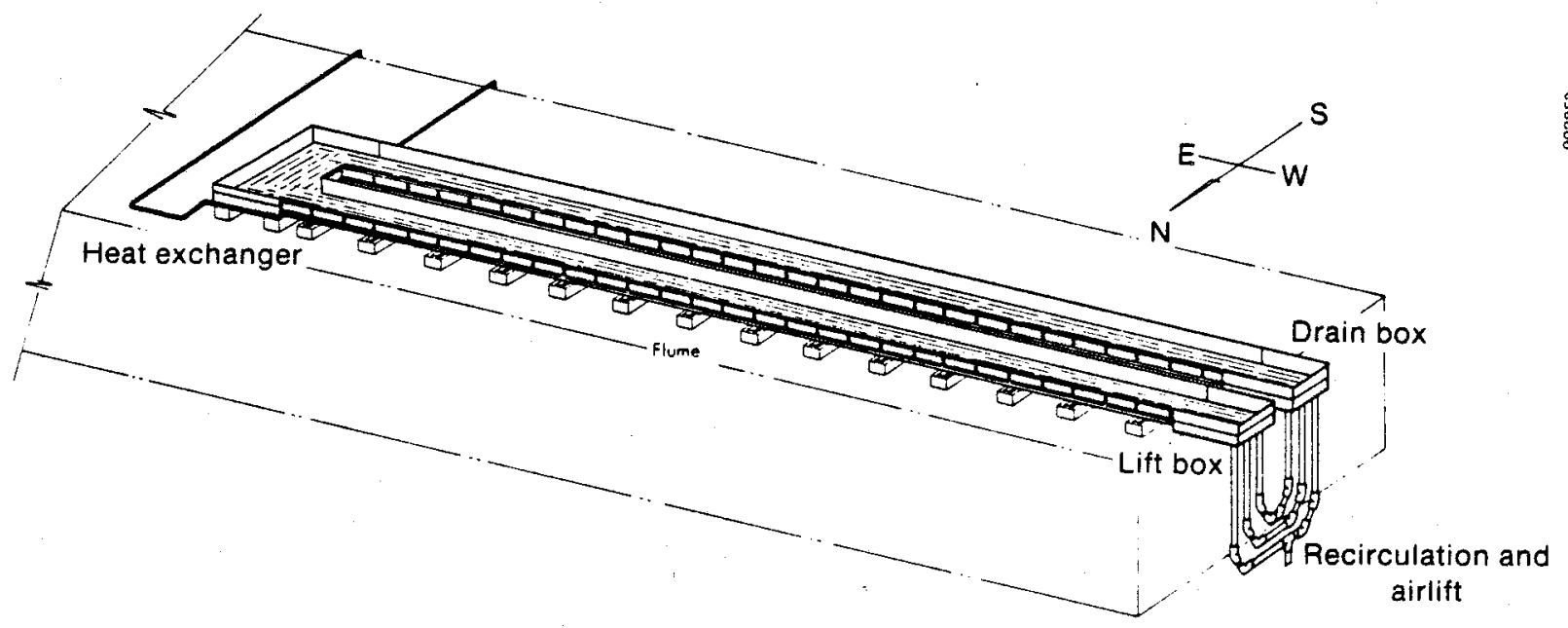

Figure 2-14. Algal Production Flume, Including Location of Heat Exchanger, Lift Box, Drain Box, and Airlift System

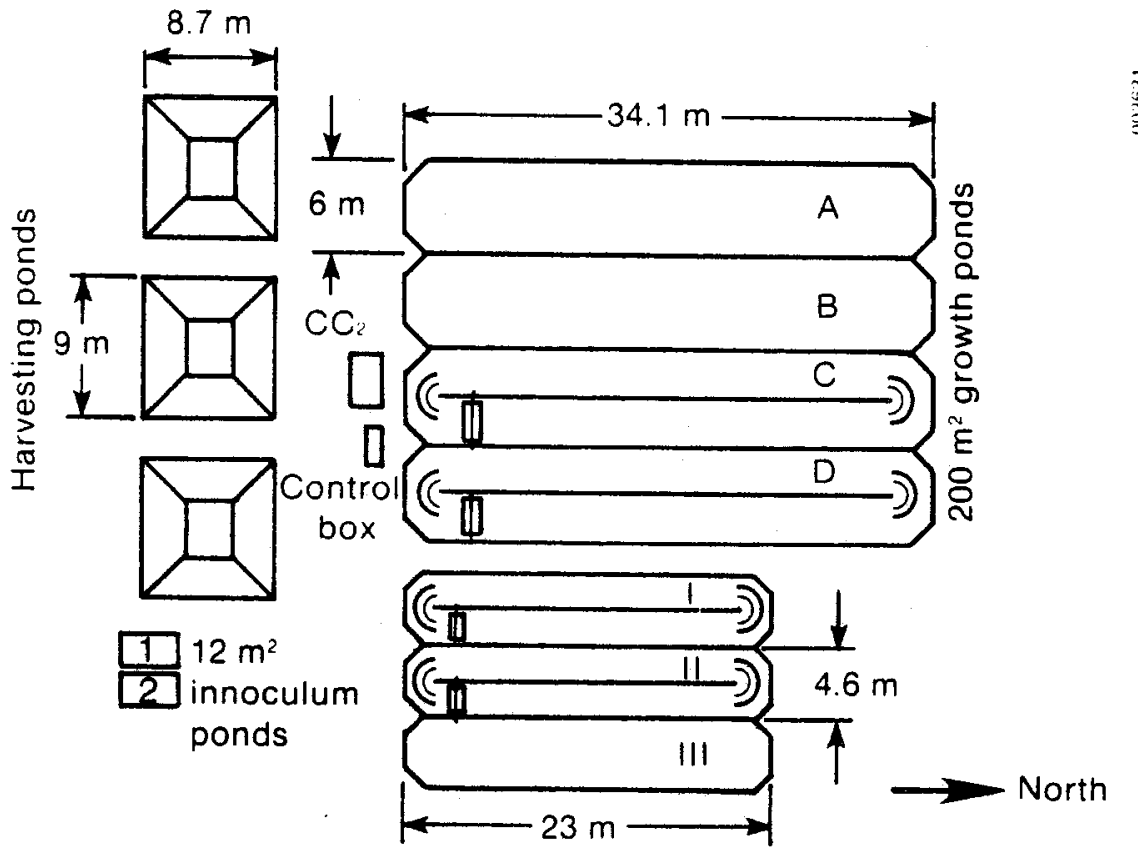

$100 \mathrm{~m}^{2}$ induction ponds

Figure 2-15. Pond System Operated by Microbial Products Co. 
The shallower raceway permits the use of foils, which effect systematic vertical mixing in the raceway. The foils are shaped like airplane wings, forcing the water flowing over them to spiral downward, creating a helical flow pattern downstream of the foil (Figure 2-16a). The optimum angle of attack is approximately 23 degrees at the flow rate and culture depth of the system, with the foil arravs placed $1.2 \mathrm{~m}$ apart. Biomass production after insertion of the foils increased $50 \%$. This enhancement is assumed to result from more efficient utilization of the flashing light effect. The flashing light effect is the increase in productivity that results from exposing microalgae to intermittent flashes of dark and light. A modeling effort to describe this flashing light effect was completed and the following points were observed: (1) At very low light intensity, there is no flashing light effect, (2) at very low cell densities there is no flashing light effect, and (3) the magnitude of enhancement from the flashing light effect increases with increased light intensity and increased cell density. The relationship between cell density, light intensity, and enhanced growth is shown in Figure 2-16b.

Performances of the two systems were established during the past vear for a number of different species (see Table 2-10). Hawaii cultured the marine diatom Phaeodactvlum and the marine flagellate Platymonas, while Microbial Products cultured two freshwater strains of Scenedesmus and a brackish water strain of Ankistrodesmus falcatus isolated from Pyramid Lake. Cultures were sustained for periods of one to three months. Cold and wet spring weather in California prevented Microbial Products from running the cultures for any extended period of time. Performance data from the two systems indicate species selection was most important. The shallower raceway established denser cultures but cultures of phaeodactylum required cooling. The large amount of energy required to cool the raceway has caused the investigators in Hawaii to look for thermophilic strains of microalgae for culture. They found that Platymonas grows at much higher temperatures $\left(28^{\circ}-30^{\circ} \mathrm{C}\right)$ than Phaeodactylum, thus eliminating the cooling requirement. One of the better performing species cultured at Microbial Products was the laboratory-selected Ankistrodesmus. It consistently had the highest lipid content, averaging $28 \%$ of the organic weight. After investigators discovered that this species requires potassium, productivities with added potassium increased over those initially obtained. Researchers at Scripps found that maximum yields for this species occurred at light intensities equivalent to $50 \%-60 \%$ full California sunlight. In dense cultures they observed that the light was attenuated by five orders of magnitude in the first centimeter of culture thickness. This indicates the importance of culture mixing and hydrodynamic studies. Work will continue with Ankistrodesmus next year, when long-term productivity data will be obtained from both the raceways and ponds.

Cost analyses indicate that operational costs associated with the two sustems represent approximately $70 \%$ of the total annualized costs. The major cost will be for nutrients, followed by utilities (pumping of water, operation of harvesting systems, and mixing requirements). Because the raceway has a much greater mixing velocity $(30 \mathrm{~cm} / \mathrm{s}$ versus $20 \mathrm{~cm} / \mathrm{s}$ ), associated mixing energy costs are 4 times greater than those for the pond. Pumping costs, however, are 4 times greater for the pond system because the volume of the system is larger.

An important aspect of the work at the University of Hawaii is to evaluate and optimize system parameters for selected species. During 1983, factorially designed experiments were conducted in four $3-\mathrm{m}^{2}$ race ways with Phaeodactylum to determine optimum system operating parameters. The factorial design allowed for efficient determination of effects of variable culture parameters; i.e., salinity, $\mathrm{pH}$, temperature, depth, mixing speed, and dilution rate. Researchers found that the most important factors to consider 


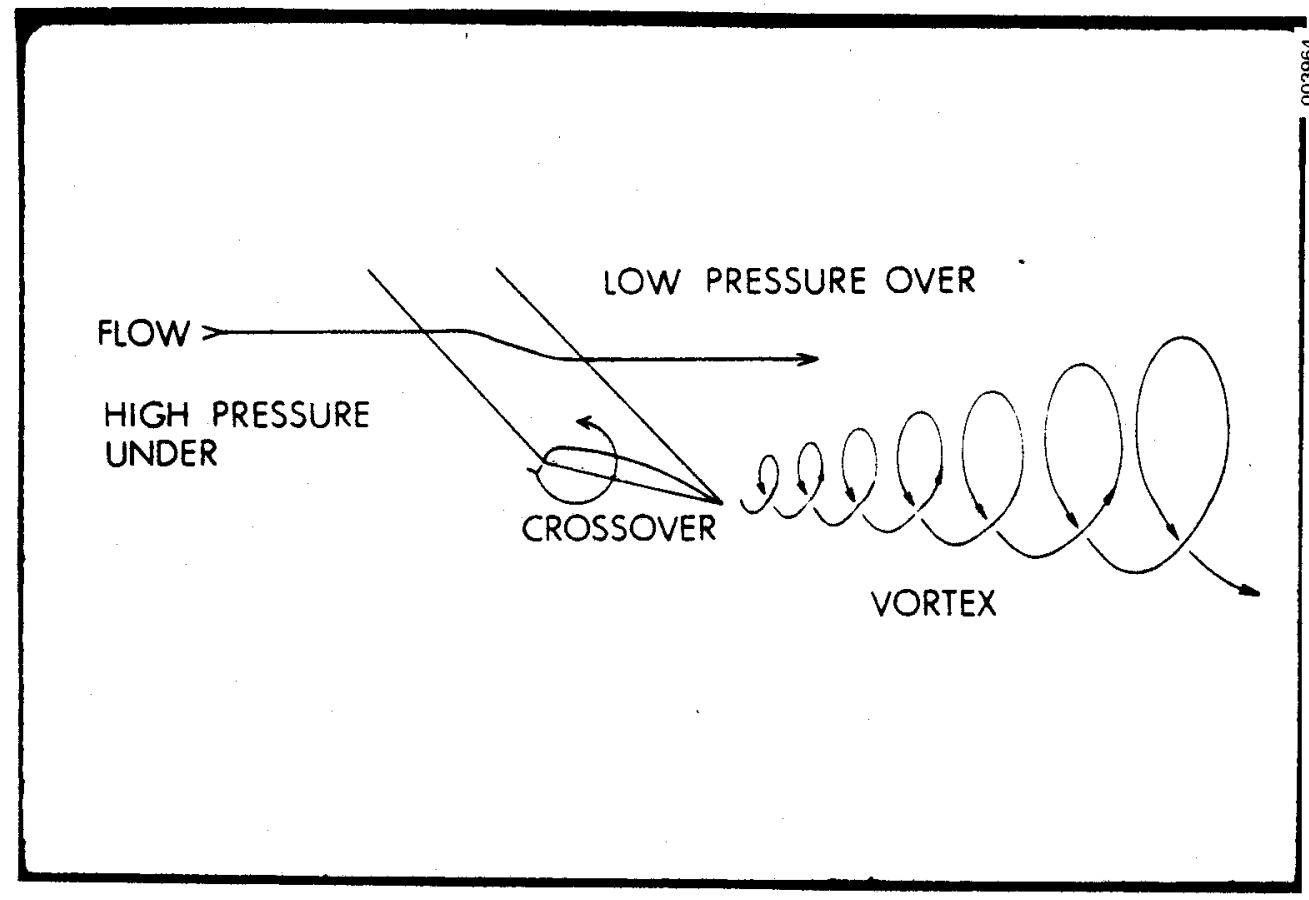

Figure 2-16a. Systematic Mixing Resulting from Foils Inserted in the Shallow Raceway

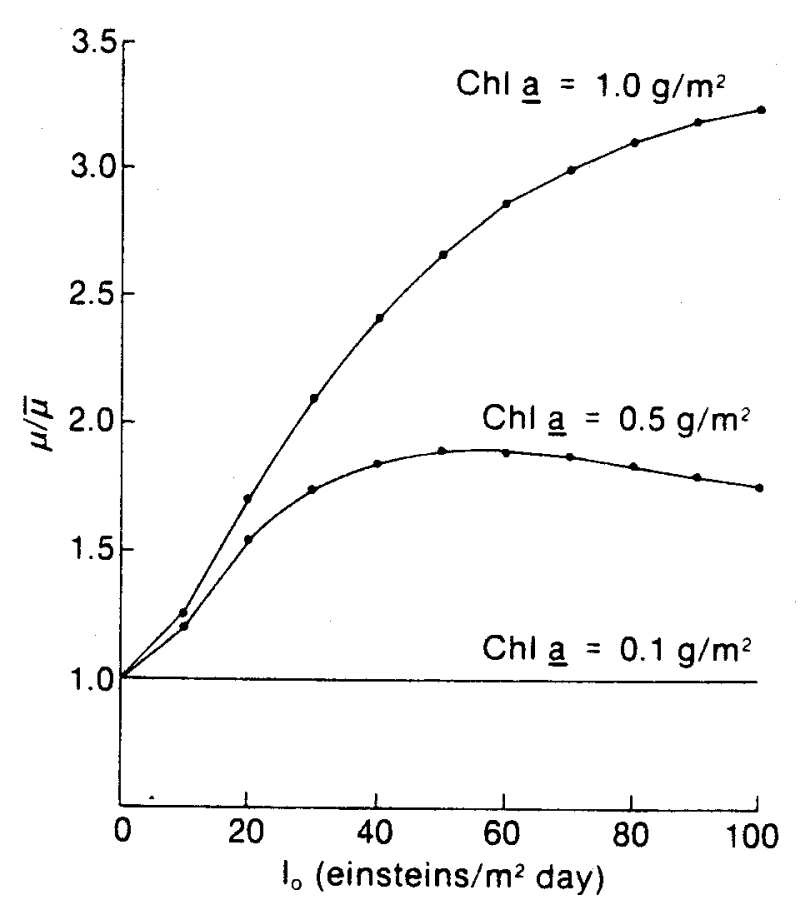

Figure 2-16b. Ratio of Growth Rate under Ideal Flashing Light Regime to Growth Rate in Absence of Flashing Light Effect as a Function of Incident Irradiance and Areal Chl a Concentration 
Table 2-10. Performance Data from Raceway and Pond Systems

\begin{tabular}{lccccc}
\hline & \multicolumn{2}{c}{ Raceway } & & \multicolumn{2}{c}{ Pond } \\
\cline { 2 - 3 } \cline { 5 - 6 } \cline { 5 - 6 } & Phaeodactylum & Platymonas & & Ankistrodesmus & Scenedesmus \\
\hline $\begin{array}{c}\text { Productivity } \\
\text { (g dry wt/m }{ }^{2} \text { day) }\end{array}$ & 20 & 25 & & 16 & 20 \\
$\begin{array}{l}\text { Lipid content (\%) } \\
\begin{array}{c}\text { Culture density } \\
\text { (mg dry wt/L) }\end{array}\end{array}$ & 22 & 20 & & 28 & 20 \\
\hline
\end{tabular}

in the design and operation of the raceway are depth, dilution rate, $\mathrm{pH}$, and temperature. The following chart lists these factors in descending order of importance for production, lipid yield, and sustained monoculture. Optimal values are given in parentheses.

\begin{tabular}{|c|c|c|c|}
\hline & Production & Lipid Yield & $\begin{array}{c}\text { Sustained } \\
\text { Monoculture }\end{array}$ \\
\hline 1. & $\begin{array}{c}\text { Depth } \\
(10-15 \mathrm{~cm})\end{array}$ & $\begin{array}{c}\text { Depth } \\
(10-15 \mathrm{~cm})\end{array}$ & $\begin{array}{c}\text { Temperature } \\
(20 \mathrm{C})\end{array}$ \\
\hline 2. & $\begin{array}{l}\text { Salinity } \\
\text { (15 ppt) }\end{array}$ & $\begin{array}{c}\text { Dilution Rate } \\
(50 \%)\end{array}$ & $\begin{array}{l}\text { Mixing Rate } \\
(30 \mathrm{~cm} / \mathrm{s})\end{array}$ \\
\hline 3. & $\underset{(7.4)}{\mathrm{pH}}$ & $\underset{(7.4)}{\mathrm{pH}}$ & $\begin{array}{l}\text { Salinity } \\
\text { (15 ppt) }\end{array}$ \\
\hline
\end{tabular}

Production rates were optimal with a dilution rate of $60 \%$ and a pH of 7.2-7.4 (see Figure 2-17). This type of work and experimentation will continue to be emphasized by the subprogram during 1984.

\subsubsection{Component Development}

One of the more significant problems in producing microalgae-derived oils is the concentration of dilute suspensions into a slurry for subsequent processing. The extent to which present technology for harvesting is economic for microalgae production depends upon the final product value and the type of species used in the growth ponds. For example, existing microalgae facilities producing health food and protein supplements use species such as Spirulina which have a sufficiently large cell size and high enough product value to compensate for a high harvesting expense. Because some of the microalgal species studied in the Aquatic Species subprogram are approximately the size of bacteria and the value of the product fuel is not as high, an effective yet cheaper harvesting technology is required.

The subprogram has developed several research tasks designed to evaluate existing harvesting methods and to propose innovative methods for increasing the density of the product stream from the growth ponds. Work on harvesting technology is being evaluated at Ben Gurion University, and during 1984 subcontracts will be issued for the design of innovative culture and harvesting concepts. 


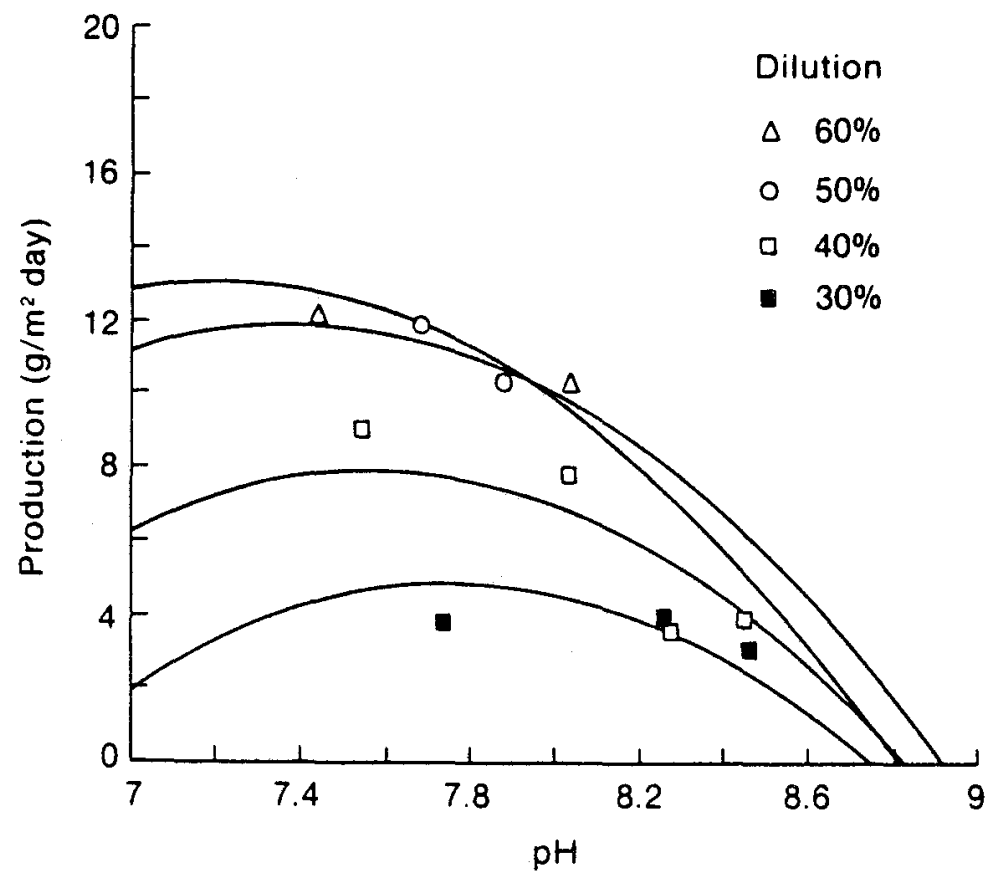

Figure 2-17. Production in Experimental Flumes as a Function of pH and Dilution Rate

\subsubsection{Technology Analysis}

The technology analysis activities provide $R \& D$ guidance for the Aquatic Species subprogram by analyzing and integrating the results of the biological and engineering research tasks. This in-house work is accomplished by conducting systems studies of the various research initiatives and identifying the $R \& D$ options that offer potential gains to the overall program objectives. There are two tasks in the activity: resource assessment and economic evaluations.

\subsubsection{Resource Assessment}

The objective of this project is to assess and evaluate the availability and location of resources required for support of microalgal oil production. A resource assessment of the American Southwest was conducted by SERIs Renewable Resource Assessment and Instrumentation Branch. The researchers collected critical resource data for microalgal production. Available land and water resources found in the region were quantitatively and qualitatively estimated, and essential climatic data was gathered. These data were assembled in map form to aid identification of suitable sites for future production facilities. Climate, land, and water maps were overlaid in a computer geographic information system to stratify the Southwest into zones of suitability for microalgal productions (mapped data is shown in Figure 2-18). The composite maps will enable future researchers to identify and quantify site-specific parameters that may affect facility design and operation.

Data bases were developed in the following areas: 
Climate. Combining evaporation and precipitation maps produced a map of makeup water requirements. A map of relative productivity was prepared by combining the parameters of insolation and freeze-free periods. A composite map of overall climatic suitability combined the two preliminary composite maps of makeup water requirements and relative productivity plus thunderstorm days. In this composite, equal weights were designated for makeup water and relative productivity; thunderstorm davs were weighted at one-quarter of the value of the other two parameters.

Water. A composite map of water suitability was obtained by combining maps of water salinity and water depth below the surface, which were derived from the original parameter map. Equal weights were assigned to the ranges of values for salinity and depth such that various combinations of these conditions were ranked in a hierarchy of desirability.

Land. Combination of the three maps of $10 \%$ slope, land ownership, and land use/cover produced a map of relative land suitability. Equal weights were assigned to land ownership and land use/cover; the $10 \%$ slope map was weighted at $40 \%$.

Overall Resource Suitability. From the three composite maps of climate suitability, water suitability, and land suitability, a final composite map was generated to show overall resource suitability for microalgae production systems. For this very preliminary composite, the three component maps were given equal weights (Figure 2-18).

In addition to this effort, Scripps chemically characterized water from the California and Nevada deserts. Salinities generally ranged from 3-10 g dissolved solids/L. The water was highly basic $(\mathrm{pH}=9)$ with sodium, chloride bicarbonate, and potassium being the predominant ions (see Table 2-11).

Table 2-11. Chemical Characteristics of Water from California and Nevada Desert Regions

\begin{tabular}{lccc}
\hline \multicolumn{1}{c}{ Characteristic } & $\begin{array}{c}\text { Pyramid } \\
\text { Lake }\end{array}$ & $\begin{array}{c}\text { Walker } \\
\text { Lake }\end{array}$ & $\begin{array}{c}\text { Black } \\
\text { Lake }\end{array}$ \\
\hline Salinity (g/L) & 5.1 & 9.6 & 19.2 \\
$\mathrm{pH}$ & 9.1 & 9.3 & 9.8 \\
Cations (mg/L) & & & \\
Calcium & 10 & 10 & 4 \\
Magnesium & 60 & 77 & 4 \\
Sodium & 1775 & 3900 & 8800 \\
Potassium & 128 & 225 & 825 \\
Anions (mg/L) & & & \\
Carbonate & 222 & 750 & 5880 \\
Bicarbonate & 854 & 1586 & 2526 \\
Sulfate & 140 & 2600 & 3200 \\
Chloride & 2150 & 2600 & 3200 \\
\hline
\end{tabular}




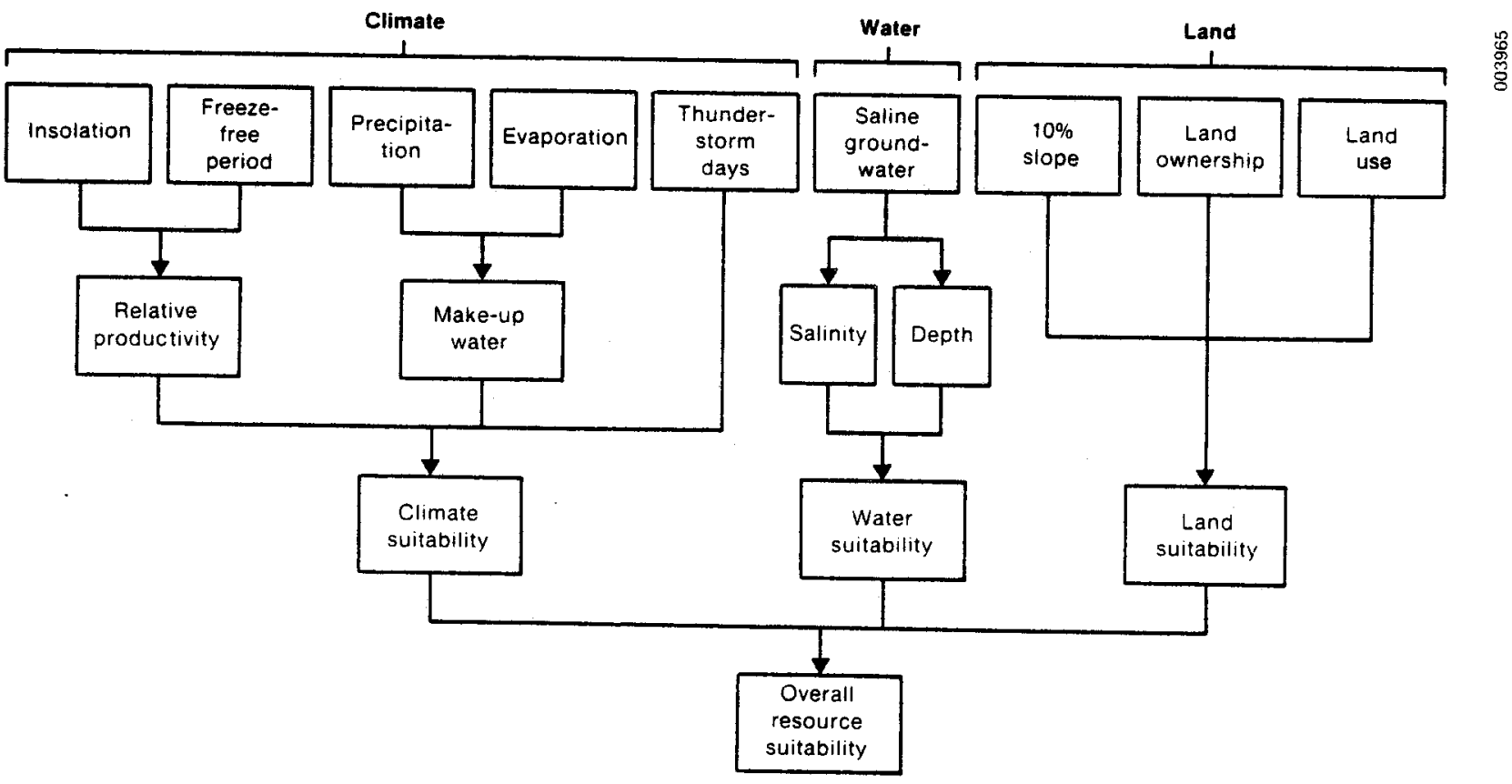

Figure 2-18a. Resource Data Mapping from Baseline Parameter Maps through Intermediate Composite Maps to the Final Composite Stratification Map

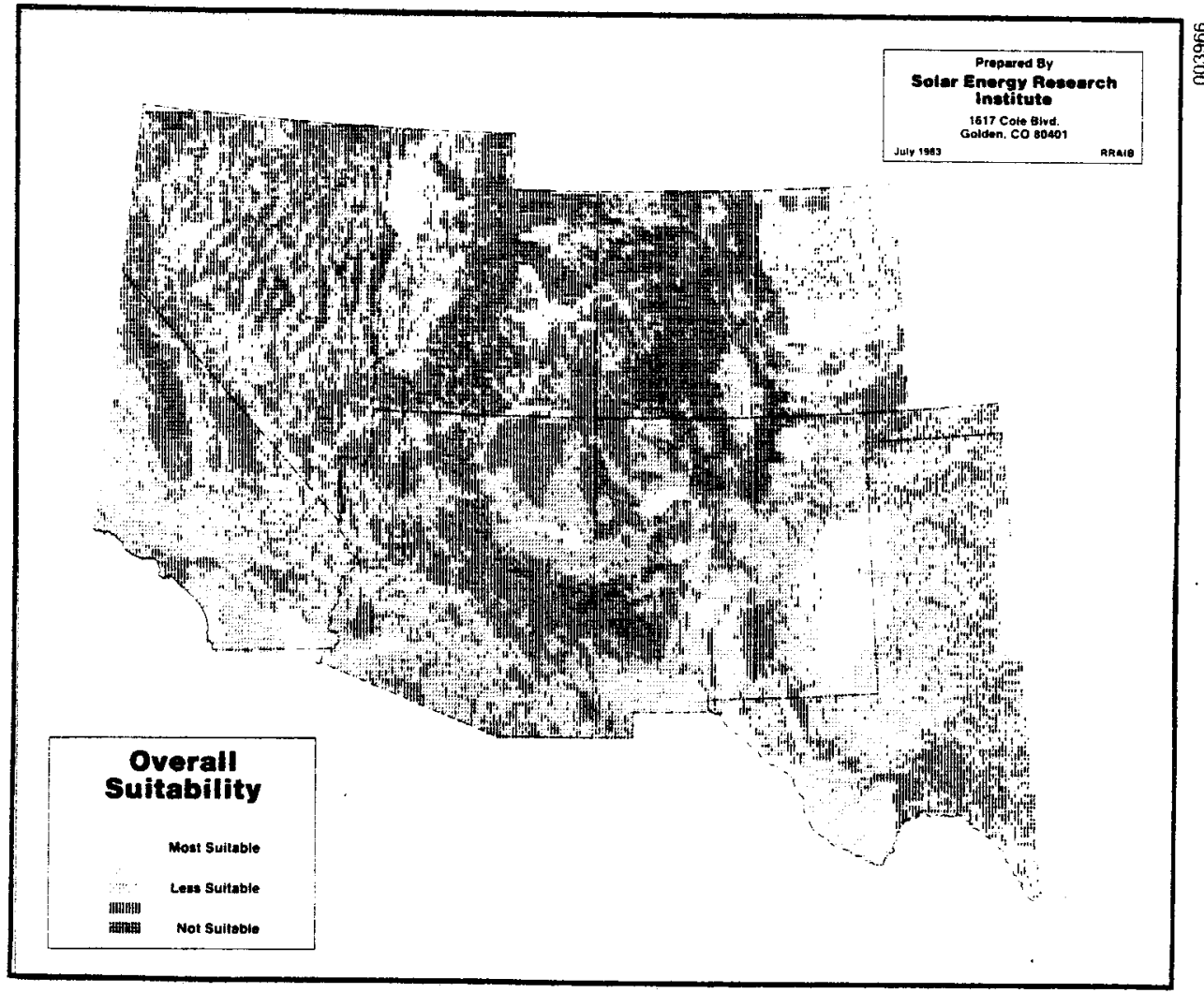

Pigure 2-18b. Computer-Generated Map of Overall Suitability for Microalgae Culture 


\subsubsection{Economic Evaluation}

The objective of this project is to evaluate and analyze microalgae production designs and establish research priorities through sensitivity analyses. During the past year, market cost goals for microalgae production were established, based on recent EIA (April 1983) price forecasts for wellhead crude petroleum. These price forecasts, to the year 2000 , were used to establish market prices for microalgae-derived fuels that would be cost competitive and independent of the particular technology. Price forecasts for establishing the market cost goals are presented in Table 2-12. These projections indicate the unit price for microalgae-derived fuels must be less than $\$ 86.0 /$ barrel (1983 $\$$ ) to compete with petroleum fuels.

An economic-production model was developed to allow evaluations of microalgal culture technologies. The model has three parts:

- Production. This provides the basis for estimating gross yields of algal biomass and uses an equation most appropriate for steady-state, continuous flow culture systems. The input parameters are depth, detention time, and culture density.

- Capital Costs. Inputs are for growth pond construction, harvesting mechanisms, and land.

- Operating Costs. Inputs include direct labor, overhead, maintenance, utility costs and nutrient expenses. This model is now being used to trace state-of-the-art costs and develop areas of cost sensitivity.

\subsection{SUMMARY}

During the past 30 years the state-of-the-art production of aquatic species has increased from about $5 \mathrm{~g}$ dry biomass $\mathrm{m}^{-2}$ day $^{-1}$ to the present $25 \mathrm{~g} \mathrm{~m}^{-2}$ day $^{-1}$. These increases are

Table 2-12. World Oil Price Projections for High, Middle, and Low World Oil Price Scenarios, 1983 to 2000 (1983\$/barrel $)^{\mathrm{a}}$

\begin{tabular}{llcc}
\hline & \multicolumn{3}{c}{ Price Scenario } \\
\cline { 2 - 4 } Year & Low & Middle & High \\
\hline 1983 & 29.0 & 31.0 & 33.0 \\
1985 & 32.0 & 26.0 & 36.0 \\
1990 & 29.0 & 39.0 & 50.0 \\
1995 & 39.0 & 58.0 & 76.0 \\
2000 & 44.0 & 62.0 & 86.0 \\
\hline
\end{tabular}

${ }^{a}$ All prices reflect the average landed price of crude oil in the United States.

Source: U.S. Department of Energy, Energy Information Administration, Annual Energy Outlook with Projections to 1990, DOE7 EIA-0383 (83), April 1983. 
the result of the application of biological principles and from knowledge gained through a number of disciplines. The AS subprogram has focused research on accelerating the advancement of these technologies.

Work with macroalgae and emergents has concentrated on the selection of the most productive species and culture management strategies that maximize yield, while keeping costs low. Two very promising macroalgal species have been found and improved, Ulva and Gracilaria. The approach used this past year of lowering costs through energy and nutrient reductions has been rewarding, and provides a model for future efforts by the AS subprogram. The most promising emergent plant for culture in the Great Lakes region seems to be Typha. Work is continuing on determining the nutrient requirements and effect of stand establishment on yields.

The emphasis of the AS subprogram since 1982 has been developing microalgae culture technology. The program has concentrated on the screening of microalgae for rapid growth in a saline media at high densities and high lipid yields. Ankistrodesmus, collected from Pyramid Lake, Isochrysis, various Chlorella strains, and Platymonas seem promising. Characterizations of microalgae will continue.

Lipids derived from microalgae are being emphasized, since lipids are high energy compounds, and various lipid fractions may either be used directly as liquid fuels or are easily converted to liquid fuels. It has been learned that lipid synthesis may be controlled through culture manipulation. This is very important, and work on the control of lipid metabolism will be continued.

Two outdoor facilities have been operated during the past year, a shallow raceway in Hawaii and a deep pond system in California. The productivities have been highly dependent on climatic conditions and species being cultured. Productivities have been 20-25 g m $\mathrm{g} \mathrm{day}^{-1}$ for the raceway, and $16-20 \mathrm{~g} \mathrm{~m}^{-2}$ day ${ }^{-1}$ for the pond. Valuable experience has been acquired in culture management strategy development. In addition, a technique has been developed in Hawaii for optimizing culture parameters to a particular species in a rapid, efficient manner.

Technology analysis activities involved work on resource assessment, including a review of existing research literature describing the local environment, climate, water resources, hydrology, and biota of the southwestern United States. Also involved is the development of a mass culturing model at SERI to provide an analytical tool for evaluating microalgal production systems, taking into account the effects and complex interactions of the many biological, physical, chemical, and engineering factors involved in algae production and harvesting and in processing algae into final products. 


\section{SECTION 3.0}

\section{PUBLICATIONS}

Connolly, J. S., Samuel, E. B., and Janzen, A. F., "Effects of Solvent on Fluorescence and Absorption Properties of Bacteriochlorophyll a,, Photochem. Photobiol. $\underline{36}$, 565-574 (1982).

Seely, G. R., and Connolly, J. S., "Luminescence of Photosynthetic Pigments in Vitro", in "Light Emission by Plants and Bacteria" (J.Amesz, D. Fork and Govindjee, eds.), Academic Press, New York (to be published, 1984).

Connolly, J. S., Janzen, A. F., and Samuel, E. B., "Fluorescence Lifetimes of Chlorophyll a: Solvent, Concentration and Oxygen Dependence", Photochem. Photobiol. 36 , 559-563 (1982).

Raymond, L. P. "Aquatic Biomass as a Source of Fuels and Chemicals." In Energy, Resources, and Environment: Proceedings of the First U.S.-China Conference, edited by S. W. Yuan. New York: Pergamon Press, 1982.

Lein, S., and K. G. Spencer. (1983) "Algal Oil Production and Lipid Metabolism Research" in "Proceedings of Aquatic Species Program Principal Investigators' Meeting", March 1983. San Diego, pp. 1-18, SERI/CP-231-1946.

Lein, S., and K. G. Spencer. (1983) "Microalgal Production of Oils and Lipids." Proceedings of IGT Symposium on "Energy from Biomass and Wastes VII." ISBN 0-910091-02-01, Institute of Gas Technology, Chicago, Illinois 60616.

Spencer, K. G., and S. Lien. "The Synthesis of Storage Lipid by Green Algae. I. The Effect of Nitrogen Depletion on a Species of Chlorella." (To be submitted for publication to Plant Physiology, October 1983.)

"Algal Mass Culture Technology: Review of Patents." Prepared for the Solar Energy Research Institute by Jaycor under Subcontract XK-Z-021 23-01, November 15, 1982.

Pratt, D. C., et al. "Emergent Aquatics: Stand Establishment, Management, and Species Screening." November 1982, SERI/STR-231-1819.

Thomas, W. H., and S. R. Gaines. "Algae from the Arid Southwestern United States: An Annotated Bibliography." Prepared under XK-2-0270-01, for SERI by Scripps Institute of Oceanography, October 1982.

Tornabene, T. G., Ami Ben-Amotz and J. S. Hubbard. "Isolation, Analysis and Identification of Lipids." Draft final report on laboratory syllabus for Microalgae Lipid Short Course, December 1982.

Ryther, J.H., "Cultivation of Macroscopic Marine Algae." SERI publication STR-231-1820. 31 pp. (November 1982).

Rebuck, T. A., and J. H. Ryther. "Effects of seawater exchange, pH, and carbon supply on the growth of Dracilaria tikvahiae in large-scale cultures." Submitted Botanica Marina (September 1983). 
Thomas, W. H., "Development of a System for Automating the Measurement of Biomass Yields and Effectiveness of Light Utilization by Microalgae," Bio Energy Council, 17 pp. (July 1983).

Thomas, W. H., and D. Seibert. "Microalgae from Desert Saline Waters as Potential Biomass Producers." Paper presented at ASES, St. Paul, Minn. (June 1983).

Thomas, W. H., and D. Seibert, M. Alden, P. Eldridge, and A. Neori. "Yields, Photosynthetic Efficiencies, and Chemical Composition of Dense Cultures of Marine Microalgae." SERI publication STR-231-1896. 57 pp. (July 1983).

Thomas, W. H., and S. R. Gaines. "Algae from the Arid Southwestern United States: An Annotated Bibliography." SERI publications STR-231-1947. 136 pp. (June 1983)

Seibert, D. C. and W. H. Thomas. Computerized Non-Invasive Measurement of the Growth Response of Microalgae to Temperature and Salinity. Submitted J. of Phycology (July 1983)

Thomas, W. H., and D. Seibert, M. Alden, P. Eldridge, and A. Neori. "Yields Photosynthetic Efficiencies, and Proximate Composition of Dense Marine Microalgal Cultures: I. Introduction and Phaeodactylum tricornutum Experiments; II. Dunaliella primolecta and Tetraselmis suecia Experiment; III. Isochrysis spp. and Monallanthus salina Experiments; and Comparative Conclusions," submitted to Biomass in August $19 \overline{83 .}$

Bonnewell, V., W. L. Koukkari, and D. C. Pratt. 1983. "Light, Oxygen, and Temperature Requirements for Typha latifolia L. Seed Germination." Can. J. Botany (in preparation for April 1983 publication).

Schertz, C., D. R. Dubbe, and D. C. Pratt. 1983. "Harvesting Cattail (Typha spp.) Rhizomes as an Alternative Feedstock for Alcohol Production: Modifications of Potato Harvester." Final report to U.S. Department of Energy, Alcohol Fuels Division. 19 p.

Spencer, K., and S. Lien submitted an abstract entitled "Utilization of Stored Oil in a Strain of Chlorella" to the American Society of Plant Physiologists.

Dubbe, D. R., N. J. Andrews, and D. C. Pratt. "Bio-Energy Production and Peatland Development." In Proceedings of Peat as an Energy Alternative II, edited by E. Carrol. New York: Macmillan Co., 1983. 